Florida International University FIU Digital Commons

\title{
Do Community Food Security Assessments Contribute to a Reduction in Food Insecurity at the County Level?
}

John D. Buschman

Florida International University, jbuschma@fiu.edu

DOI: $10.25148 /$ etd.FIDC006541

Follow this and additional works at: https://digitalcommons.fiu.edu/etd

Part of the Food Studies Commons, and the Social Work Commons

\section{Recommended Citation}

Buschman, John D., "Do Community Food Security Assessments Contribute to a Reduction in Food Insecurity at the County Level?" (2018). FIU Electronic Theses and Dissertations. 3705.

https://digitalcommons.fiu.edu/etd/3705 
FLORIDA INTERNATIONAL UNIVERSITY

Miami, Florida

DO COMMUNITY FOOD SECURITY ASSESSMENTS CONTRIBUTE TO A REDUCTION IN FOOD INSECURITY AT THE COUNTY LEVEL?

A dissertation submitted in partial fulfillment of the requirements for the degree of DOCTOR OF PHILOSOPHY

in

SOCIAL WELFARE

by

John D. Buschman

2018 
To: Dean Tomás Guilarte

Robert Stempel College of Public Health and Social Work

This dissertation, written by John D. Buschman, and entitled Do Community Food Security Assessments Contribute to a Reduction in Food Insecurity at the County Level?, having been approved in respect to style and intellectual content, is referred to you for judgment.

We have read this dissertation and recommend that it be approved.

Mark J. Macgowan

Paul H. Stuart

Joseph J. West

Jinlin Zhao

Eric F. Wagner, Major Professor

Date of Defense: March 26, 2018

The dissertation of John D. Buschman is approved.

Dean Tomás Guilarte Robert Stempel College of Public Health and Social Work

Andrés G. Gil

Vice President for Research and Economic Development and Dean of the University Graduate School

Florida International University, 2018 
(C) Copyright 2018 by John D. Buschman

All rights reserved. 


\section{DEDICATION}

I dedicate this dissertation to my late parents Dr. and Mrs. Melvin C. Buschman who followed this path six decades before me, when research was done spending endless nights in carrels and stacks, when statistical calculations were made with a slide rule, and when documents were produced through an unforgiving, mechanical process on a preelectronic version of a machine known as a typewriter.

I honor my family pioneers of The Greatest Generation who did it the hard way, surviving the Oklahoma Dust Bowl, the Great Depression, WWII, and a doctoral research and dissertation writing process that current generations cannot begin to fathom. I greatly appreciate the many valuable lessons they provided and the encouragement they gave me,

even in their final few years, to pursue my own dreams so much later in life than they did themselves. 


\section{ACKNOWLEDGMENTS}

I would like to first thank my many hospitality mentors Associate Dean Rocco Angelo, Associate Professor Chekitan Dev, Vice Provost Steven Moll, Associate Dean Diann Newman, Associate Dean Joan Remington, Professor Donald Rosellini, Faculty Chair John Thomas, Dean Joseph West and Director of Graduate Programs Jinlin Zhao for believing in me, for encouraging me to pursue this advanced degree later in life and for seeing true value in the interdisciplinary approach that I have taken. I am equally appreciative of my School of Social Work mentors including Director Mary Helen Hayden and Ph.D. Program Coordinator Rich Beaulaurier for their caring administrative guidance as well as Professor Paul Stuart and Associate Dean Mark Macgowan for expertly and patiently shepherding me in the direction that has resulted in this dissertation. Finally, I am forever grateful to my major professor, FIU Bridge Director Eric Wagner, for his unique leadership, support, wisdom and especially for the music that kept me going throughout my trajectory at both C-Birg and FIU Bridge.

In fact, I am most appreciative of the entire FIU Bridge and C-Birg families who have encouraged and supported me in so many ways throughout my journey. Special thanks are reserved for Dr. Michelle Hospital, Dr. Staci Morris, and Ms. Eva Wales who endeavored to keep me grounded, oriented and functioning throughout the long process. Dr. Meenal Sawant and Dr. Rachel Clarke have been so kind to lend me some of their many skills in the final stages.

Ms. Maria Gutierrez, Ms. Zenaida Pirri, Ms. Gladys Ramos, Ms. Thelma Robles and Ms. Kelly Sydnor; your wonderful support has been of great value to me and surely to our many other students. Operationally, I must add thanks to Mr. Roland Ramirez for 
keeping me going electronically in the earlier stages and to Ms. Sheyla Aguilar de Santana for her patient and expert help on ArcGIS.

I have been inspired, encouraged, nudged, cajoled and otherwise supported by many individuals and organizations outside of the university and I would like to attempt to acknowledge as many as I can. My gratitude goes first to Mr. Francisco "Paco" Velez and Ms. Sari Vatske at Feeding South Florida as well as Mr. Carlos Santamaria and Ms. Mindy Ortiz of Second Harvest Food Bank of Central Florida. Much of what I know about on-the-ground community food relief efforts has been learned through years of volunteer work with these two incredible organizations and their highly-dedicated professional teams. Paco's support was instrumental in securing the secondary data for this study from the parent organization; thanks too must therefore go to Feeding America.

Others who have been inspirational to me on community food work have been Ms. Joanna Berens, Mr. John Delgado, Ms. Melanie Geddes, Ms. Susan Gladstone, Mr. Mitchell Haller, Ms. Jill Horwitz, Pastor Debbie Joseph, Chef Mike Moran, Ms. Kelly Murphy, Mr. Brian Phelan, Mr. Steven Pollack, Ms. Rachel Shapiro, Chef Allen Susser and Mr. Andy Villabona. I apologize in advance for I have surely slighted a few key individuals; I will simply have to blame that omission on being at the end of a very long dissertation process. Thank-you all for your encouragement, all along the way.

Last, and certainly not least, I must profusely thank my study buddies Dr. Meenal Sawant and soon-to-be-Ph.D.s Michelle Thompson and Mitra Ahmadinejad. The nourishing energy derived of your never-ending encouragement and late-night library snacks cannot be underestimated. 


\section{ABSTRACT OF THE DISSERTATION \\ DO COMMUNITY FOOD SECURITY ASSESSMENTS CONTRIBUTE TO A REDUCTION IN FOOD INSECURITY AT THE COUNTY LEVEL?}

by

John D. Buschman

Florida International University, 2018

Miami, Florida

\section{Professor Eric F. Wagner, Major Professor}

Food insecurity $(\mathrm{FI})$ is a significant risk factor in malnutrition which can lead to obesity and type 2 diabetes. The association of FI to undernutrition can additionally lead to impaired cognitive development in children. Nearly $\$ 100$ billion is spent annually on federal nutrition programs yet FI still affects 1 in 8 American households pointing to the urgent need for the further refinement of our national/regional anti-hunger models. One notable and underutilized tool is the community food security assessment (CFA) which seeks to eliminate FI at the local level by improving food access throughout the community. A major limitation in knowledge about CFAs is the dearth of empirical studies of their effectiveness.

The principal aim of this dissertation research was to statistically examine secondary data on U.S. counties where CFAs have been conducted and to determine whether they helped reduce individual FI over a two-year, post-test period. Repeated measures of ANOVA across the longitudinal time frame for $n=66$ counties revealed the main effect of FI was not statistically significant. A majority (56.9\%) of 37 counties experienced a decrease in FI over the period. Linear regression found that unemployment 
was a significant influence in communities that experienced decreases in individual FI at the county level during the pre-test/post-test interval $(\beta=.387$ [.067], $\mathrm{p}<.01)$.

This dissertation found that CFAs can be more effective in areas of higher unemployment as well as geographically where FI is initially higher, however further research is clearly needed in more communities over a longer time period. Also, the study suggests that proper development and structure of state and local-level food policy councils (FPCs) may lead CFAs to find better structure, funding and best practices to become more effective.

Overlays prepared with ARC-GIS mapping demonstrate that, in general, CFAs are not being performed in areas of highest FI when measured at the county level. The most important take-away from the visual mapping is the dearth of studies performed in the southeastern and southwestern regions of the country where county-level FI is higher, on average, than the rest of the country. These regions coincide with much of the Southern Black Belt and areas where Hispanic or Latino populations are most prevalent suggesting that communities in these regions may be able to benefit from the intervention. 


\section{TABLE OF CONTENTS}

$\begin{array}{ll}\text { CHAPTER } & \text { PAGE }\end{array}$

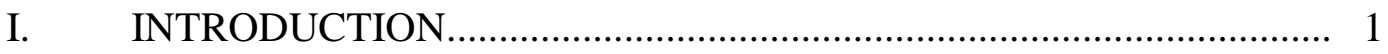

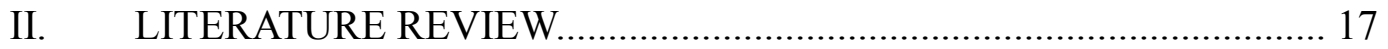

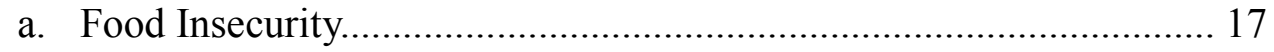

b. Health Consequences of FI................................ 22

c. Previous CFA Reviews...................................... 28

d. Conceptual approaches and methods of previous researchers.......... 33

e. Strengths and limitations of the findings in the literature .......... 40

f. Theoretical Models ............................................. 40

III. METHODS .............................................................................. 49

a. Research Design..............................................49

b. Measures................................................... 50

c. Data Management............................................5 53

d. Analytic Strategy...........................................53

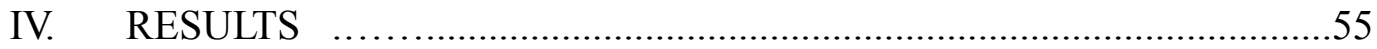

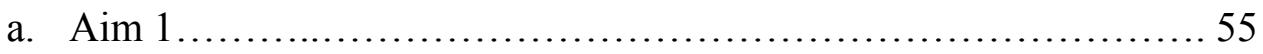

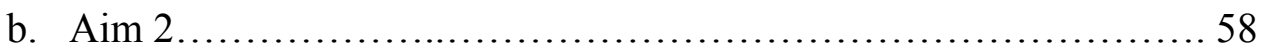

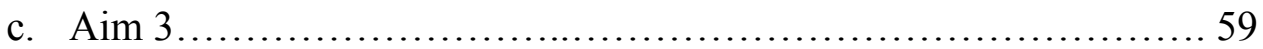

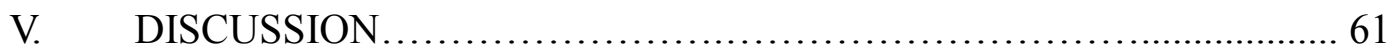

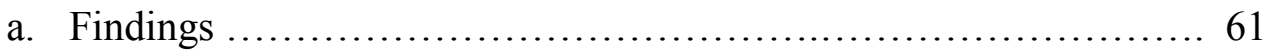

b. Implications for Social Work Practice ..........................6 62

c. Policy Implications ..................................... 63

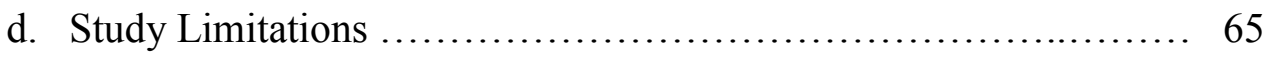

e. Implications for Future Research ........................... 66

REFERENCES ............................................ 70

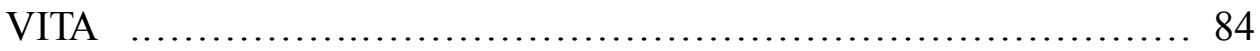




\section{LIST OF FIGURES}

FIGURE

PAGE

1. Analytical Process from CFA Delivery to the Community 5

2. CFA Model, Pothukuchi et al. (2002) 13

3. Individuals by food security status of household, 1998-2016 18

4. Food Insecurity at the County Level - 2014

5. Conner \& Levine's Community-based Food Systems model 44

6. U.S. Counties in the study by CFA year 55

7. U.S. counties in the study over county-level FI rates nationwide 57

8. Percentage difference between pre-test and post-test for county-level CFAs 58 in the study. 


\section{CHAPTER I: INTRODUCTION}

Food insecurity (FI) persists as a serious social issue in the U.S. despite nine years of economic expansion following the Great Recession of 2007-2009. Cautious but steady economic growth over the period has brought incremental improvements in job creation as well as reductions in FI's key indicators of poverty and unemployment (Strauss \& Haasl, 2018). Notwithstanding these and other steadily-rising economic indicators (e.g., GDP, housing starts, U.S. Treasury rates) the U.S. Department of Agriculture (USDA) estimated that 41.2 million Americans lived in households that had some difficulty during 2016 acquiring adequate amounts of nutritious food needed to live active and healthful lives (Coleman-Jensen, Rabbitt, Gregory, \& Singh, 2017).

Prior to the Great Recession, the total number of food-insecure individuals in the U.S. was already on the rise, having increased gradually from an estimated 31.0 million in 1999 to 35.5 million in 2006 . The total then surged by more than $40 \%$ to a record-high total of 50.1 million individuals or an estimated $16.6 \%$ of the U.S. population for the year 2009 (see Figure 2). The USDA's annual report, Household Food Security in the U.S., reported at least 48 million food-insecure individuals resided in the U.S. between 2009 and 2015. The 2016 report showed the first marked reduction in FI in more than a decade (Coleman-Jensen et al., 2016). There is cause for concern, however, as the 2017 report shows statistically-insignificant improvement in FI levels over the previous year, despite continued economic recovery. The 2016 rate of individual food insecurity in the U.S., at $12.9 \%$ or 41.2 million individuals, continues to be much higher than all yearly USDA estimates made prior to the Great Recession (Coleman-Jensen et al., 2017). 
The federal government addresses FI through the USDA's Food and Nutrition Service (FNS) which administers 15 domestic food assistance programs with a combined annual budget for fiscal year (FY) 2018 of $\$ 99.8$ billion. (USDA, 2017). Programs such as the Supplemental Nutrition Assistance Program (SNAP), colloquially still referred to as "food stamps", the Special Supplemental Nutrition Program for Women, Infants, and Children (WIC), and the National School Lunch Program (NSLP) with its extensions for school-based breakfast and after-school snacks, are today commonplace in American communities. School officials, nutritionists, social workers and other professionals across the U.S. are dedicated to ensure that these programs reach all those who qualify. Feeding America (FA), the nation's largest food banking network, was established to supplement these federal programs by assisting regional and local governments, charities and businesses in their efforts to reduce FI at the local level. The non-profit system of over 200 regional food banks distributes enough food to provide for at least three billion meals a year through their network of more than 46,000 non-profit agencies that in turn operate some 58,000 community programs throughout the country (FA, 2014).

For decades these sweeping national, state and regional endeavors, both public and private, have had a profound impact on FI. Yet, their combined efforts have failed to conquer the problem. Despite almost 10 years of improving economic conditions, nearly one in eight people in the U.S. are still considered to be food insecure including approximately 13 million children and five million seniors (Coleman-Jensen et al., 2017). Moreover, the most-recent USDA report revealed minimal change in overall household and individual FI for 2016 and even a slight increase in the number (6.5 million) and 
percentage $(8.8 \%)$ of children living in households with food-insecure children (Coleman-Jensen et al., 2017).

Efforts are underway in the federal government to make adjustments to long-term funding of the FNS's programs. It has long been anticipated that a Republican-controlled Congress will attempt to reduce many of the federal programs when the quinquennial Farm Bill comes up for renewal in late 2018 (Jalonick, 2016). The Center on Budget and Policy Priorities (CBPP) has suggested that the approach will be to pass significant taxreduction legislation in the short term which would later serve to justify the reduction of services to the lower-income classes in the form of nutrition benefits, Medicaid and education programs (CBPP, 2017).

USDA Secretary Sonny Perdue has indicated that he plans to improve the efficiency of nutrition programs and promote working pathways to self-sufficiency through better state-level case management related to programs' distribution methods such as through block grants to the individual states (USDA, 2018). In any case there is ample precedent to suggest that Congress will push farm bill debate into 2019, particularly because the prescribed renewal date is during a mid-term election year (Abbott, 2017).

The continued high incidence of FI, coupled with such indications of potential cuts in services to the food-insecure population, suggests that further refinements of the U.S. anti-hunger model are going to be needed to help reduce the problem and that a more localized approach may be needed. One notable and underutilized intervention is the community food security assessment (CFA), defined by Pothukuchi and associates, in their "Guide to Community Food Assessment", as “... a collaborative and participatory 
process that systematically examines a broad range of community food issues and assets, so as to inform change actions to make the community more food secure" (2002, p. 11).

Working at the local level, the CFA has the overarching goal to eventually eliminate FI by improving access to nutritious food throughout the entire community (Pothukuchi, 2004; Pothukuchi, Joseph, Burton \& Fisher, 2002; Jacobson and Hassanein, 2004). A major limitation in knowledge about CFAs is the dearth of empirical studies of their effectiveness in approaching that goal, that is, to reduce FI within the communities they seek to improve. One reason for this has been the lack of community-level data on FI.

In response to the deficiency of studies, this dissertation research examined what happens to the FI of community residents after the CFA is delivered to the community. Specifically, it seeks to find out if there is evidence that would suggest that CFAs contribute to a reduction in FI for the community's residents.

Community change effectively begins with the formation of the CFA committee that will conduct the research and develop recommendations for community action. The CFA immediately brings together a variety of food-system stakeholders to work towards a common goal of improved CFS, often for the first time. While each stakeholder may bring his or her own individual "take" on the process, the fact is that diverse interests are sitting at the same table and working on a common goal; frequently this represents a dramatic change in communities experiencing CFS issues. The FPC generally works between private/public stakeholders and government authorities to effect any needed policy changes (e.g. zoning modifications, appropriations for school meals, etc.) before fully developing the action steps that may require them. 
A view of the process may be seen in Figure 1, beginning in the upper left with the production and delivery of the CFA to the community. The potentially-influencing factors in the bottom portion of the diagram include measures for diversity (race and ethnicity), median income, home ownership, unemployment and poverty, the same factors observed in the MMG studies.

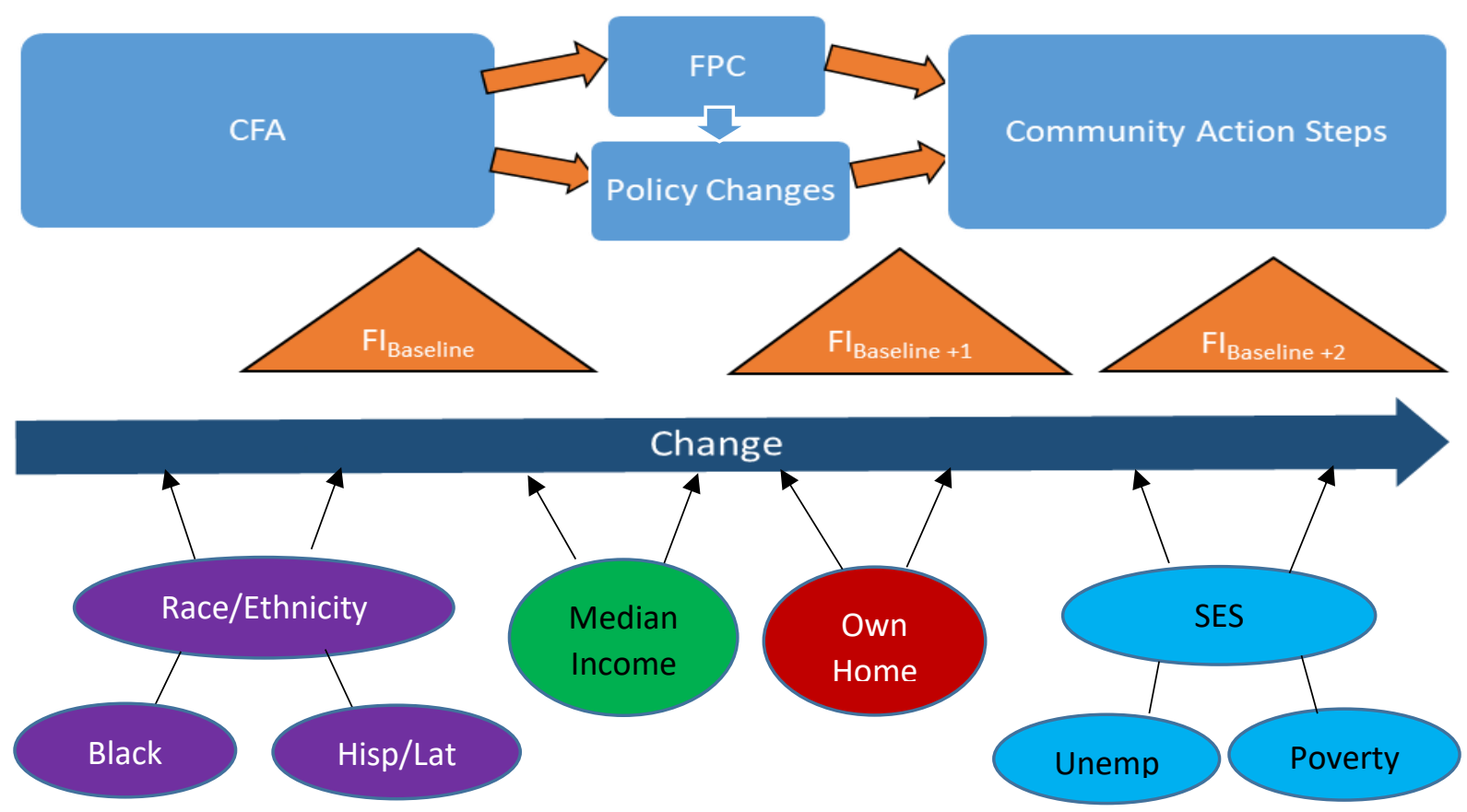

Figure 1- Analytical Process from CFA Delivery to the Community

In this model, individual FI for the community engaging in the CFA (i.e., the percentage of food-insecure individuals within the county's boundaries) is measured at three points which are represented in the diagram by the orange-colored triangles. The first measurement will represent individual FI at the time of the conclusion/delivery to the community of the assessment (labeled FI baseline). The second, one year later (FI baseline+1), and the third, after two years (FI baseline+2). It is assumed, for the purpose 
of this research, that in most communities a majority of the recommended steps are under way only by the second year of work following the CFA's conclusion.

Previous attempts to measure any successes or failures of CFAs were limited to evaluating individual community food initiatives that had been recommended and developed either during the assessment period or after the delivery of the CFA report. Moreover, such efforts typically were limited to individual action steps that were part of USDA or other sponsor-funded food programs requiring post-hoc evaluation and reporting. They largely failed to consider planning initiatives such as the re-routing of bus routes to allow better shopping options for residents of food deserts, the attraction of a supermarket chain to open a store in a food desert, or a change in zoning statutes to allow community gardens. The majority of the evaluations also failed to consider the cumulative effect of the many action steps and initiatives on the overall CFS of the community. This research proposed to evaluate the aggregate effect of the entire CFA process on the measured individual FI of the community's population.

This dissertation research was developed from a social welfare perspective grounded by social justice and person-in-environment systems theories, in particular Conner and Levine's (2006) framework for the construct they call Community-based Food Systems. The study examined FA's Map the Meal Gap (MMG) project data from 2009 - 2014 on at least 60 American communities where CFAs have been conducted, to determine whether they do in fact help reduce individual FI over a post-CFA period of two years.

It was not known whether MMG data would suggest that CFAs may have led to reductions in FI in many of the neighborhoods, towns, cities and counties where they 
have been conducted. Positive results, if found, could provide a critical scientific foundation to support further use of the CFA by concerned communities elsewhere in the U.S. The absence of positive results might suggest the opposite, or at minimum, suggest further or alternative study.

\section{Research Question}

This study set out to answer the question: Does the CFA positively impact the food-insecure population within two years of the dissemination of its concluding report and recommendations to the community? In other words, given a reasonable amount of time (two years) for the community to develop the CFA's recommended initiatives, has the CFA contributed to an effective reduction in individual FI in the community?

The central hypothesis of this dissertation is that the CFA will improve CFS for all members of the community, particularly the most food insecure among them. The best indicator that improvement has indeed reached the least food secure of the community is to compare the community-level estimates of individual FI across time once the CFA has been concluded.

\section{Research Aims.}

Aim 1. A preliminary aim of the research is to geographically map the findings to provide a better understanding of the types of locations where the CFAs selected for this study have been conducted. This visual presentation of the data is expected to give a more complete picture of the situations where CFAs may have worked, or not worked, to reduce FI in the communities where they were conducted. 
Aim 2. The principal aim of the proposed research is to examine MMG data for communities that completed a CFA so as to determine whether CFAs help reduce individual FI over a two-year post-CFA period.

Hypothesis: Communities conducting CFAs experience a reduction in individual FI within two years of the dissemination of results and recommendations for community action steps.

Aim 3. The secondary aim of the research is to explore the data to see what it suggests about the characteristics of communities that are having greater or lesser success following the implementation of a CFA, according to the following parameters: Parameter 2a. Urban communities versus rural communities.

Parameter $2 b$. Communities with larger populations as compared to smaller ones. Parameter $2 c$. Communities that are more racially and ethnically diverse.

Parameter $2 d$. Communities where the incidence of unemployment is higher.

Parameter 2e. Communities where the median household income is lower.

Parameter 2f. Communities where the incidence of home ownership is lower.

Parameter $2 g$. Communities where poverty is higher.

\section{Significance of Problem}

FI can be the start of many detrimental health consequences among adults, children and families. Researchers have found that at-risk populations frequently experience problems with physical health such as malnutrition, diabetes mellitus, and obesity; one study reported that food-insecure adults were nearly 2.5 times more likely to be obese as those who were food secure (Centers for Disease Control \& Prevention [CDC], 2011; Martin \& Ferris, 2007) Obesity, in turn, has been linked to higher health 
care costs as well as many extended, negative effects on physical ability, mobility, and other quality-of-life measures (Pan, 2009; Office of the Surgeon General [OSG], 2001). FI also has been linked to problems with cognition, academic performance and psychosocial development among school children (Howard, 2010; Alaimo, Olson, \& Frongillo, 2001). Research has further shown that FI can be related to depression and anxiety among adolescents and adults (Zaslow, 2009; Rose-Jacobs, Black, \& Casey, 2009).

CFAs seek ways to increase food access in communities, including those that qualify as food deserts, a term used by the USDA to describe census tracts where residents lack access to sufficient, nutritious food due to a dearth of larger grocery stores, supermarkets or farmers' markets (ERS/USDA, 2013a; ERS/USDA, 2011). To accomplish that goal some CFAs have determined a need to increase the distribution of fresh produce or other foods of higher nutritional value into those neighborhoods. The CFA may recommend short-term action steps such as setting up food pantries, farmers' markets or community gardens. A CFA might also conclude that longer-term solutions are needed such as negotiating with a supermarket company to open a new store within the community, or that a food distribution or processing plant should be encouraged to operate in the area to bring food distribution as well as new jobs closer to the community.

Accomplishing these types of initiatives necessitates the early involvement and cooperation of stakeholders from throughout the agricultural as well as the food processing and distributing sectors of the food system. Policymakers and government administrators responsible for those areas must be involved as well insofar as policy changes may be necessary to reduce or eliminate zoning or statutory barriers that may be 
impeding more efficient production and distribution of nutritious foods in the local community. Bankers or other investors may be drawn in due to the potential for economic development and the increased employment opportunities within the community.

Academic researchers and other consultants are frequently involved in designing and leading a community's CFA effort, or at least in developing some of the component studies such as quantitative public surveys and market evaluations or qualitative interviews and focus groups. School administrators, nutritionists and dieticians are important participants given their responsibilities for overseeing school breakfast, lunch and after-school snack programs for qualifying students under their charge. Public health, hospital or other medical institution personnel also may be invited to participate given their expertise and understanding of the potential consequences of FI (Mabachi \& Kimminau, 2012).

Consumers themselves must have representation at the planning table as well as a hand in the research process given that most CFAs are designed to use community-based participatory research (CBPR) methodology (Cohen, 2002; Pothukuchi et al., 2002). Care should be taken to ensure the inclusion of members of both the food-secure population, who face little or no restrictions on where they may shop for food, and the food insecure who typically experience some level of difficulty accessing food of adequate variety and nutritional value. Finally, the social work profession should be involved to advocate for the food-insecure population and the many community agencies that serve them including food pantries, soup kitchens and shelters (Jacobson \& Hassanein, 2004). 


\section{Development of Scientific Knowledge of the Problem}

Conceptualizations of FI have experienced several paradigmatic shifts since the term was first defined at the United Nations' (UN) 1974 World Food Summit in Rome (UN, 1975). The initial application of the term was meant to focus attention on the volume and stability of food supplies in certain nations and world regions during a time of global food crisis. Sen (1981) is widely credited as having moved the focus from that of a world regional and country-level food supply to a single person or a household's ability to access a food supply in their local area. It follows that poverty came to be recognized as a prime factor and indicator leading to FI (Webb, Coates, Frongillo, Rogers, Swindale, \& Bilinsky, 2006).

A second substantial change occurred during the 1990s when Sen's conceptualization of FI was broadened to additionally embrace exo- and macro-level views. This expanded approach came about as researchers explored more and more components of the food system and began to discuss the relative food security of the household and the community within which the individual resides (Anderson \& Cook, 1999). Maxwell described this shift as going from a somewhat narrow emphasis on food supply to a much broader and more complex focus on "livelihood" (1996, p. 157). Maxwell noted also a major change in measurement, from standard indicators of food supply and consumption to more subjective perceptions by the individual or family as to how they find they are managing their household's recurrent food acquisition such as with issues of access, nutritional quality or cultural acceptability of available foods. 
A third and ongoing development has been an increasing public interest in the sustainable urban food environment as well as many advances in research looking at the relationships between food security and both environmental and economic sustainability (Marsden \& Morley, 2014). Terms such as foodshed (Getz, 1991), community-supported agriculture (DeMuth, 1993), food miles (Paxton, 1994), food circle (Bentley, 1995), community food system (Peters, 1997), food democracy (Lang, 1998) and food citizenship (Welsh \& MacRae, 1998) entered the literature at various points providing evidence of FI's broadened view and systems approach. Particularly in the U.S. and Canada, a significant number of neighborhoods, cities and counties have developed or are developing strategic plans towards sustainable, healthy food systems under the bannergoal of community food security (CFS).

The CFA, alternatively called community food security or community food system assessment, emerged in the late 1990s from the community food security (CFS) movement to support three strategic goals: a) strengthen food systems at the local level, b) decrease overall need (i.e., reduce FI), and c) improve human nutrition (Kantor, 1999, Cohen, 2002). Some early adopters of the CFA model stressed that its overarching goal is to eventually eliminate FI by supporting broad access to food throughout the entire community (Pothukuchi, 2004; Pothukuchi et al., 2002, Jacobson and Hassanein (2004). The Pothukuchi et al. model places the promotion of community food security at the intersection of all community food system objectives and food system activities (see Figure 2). 


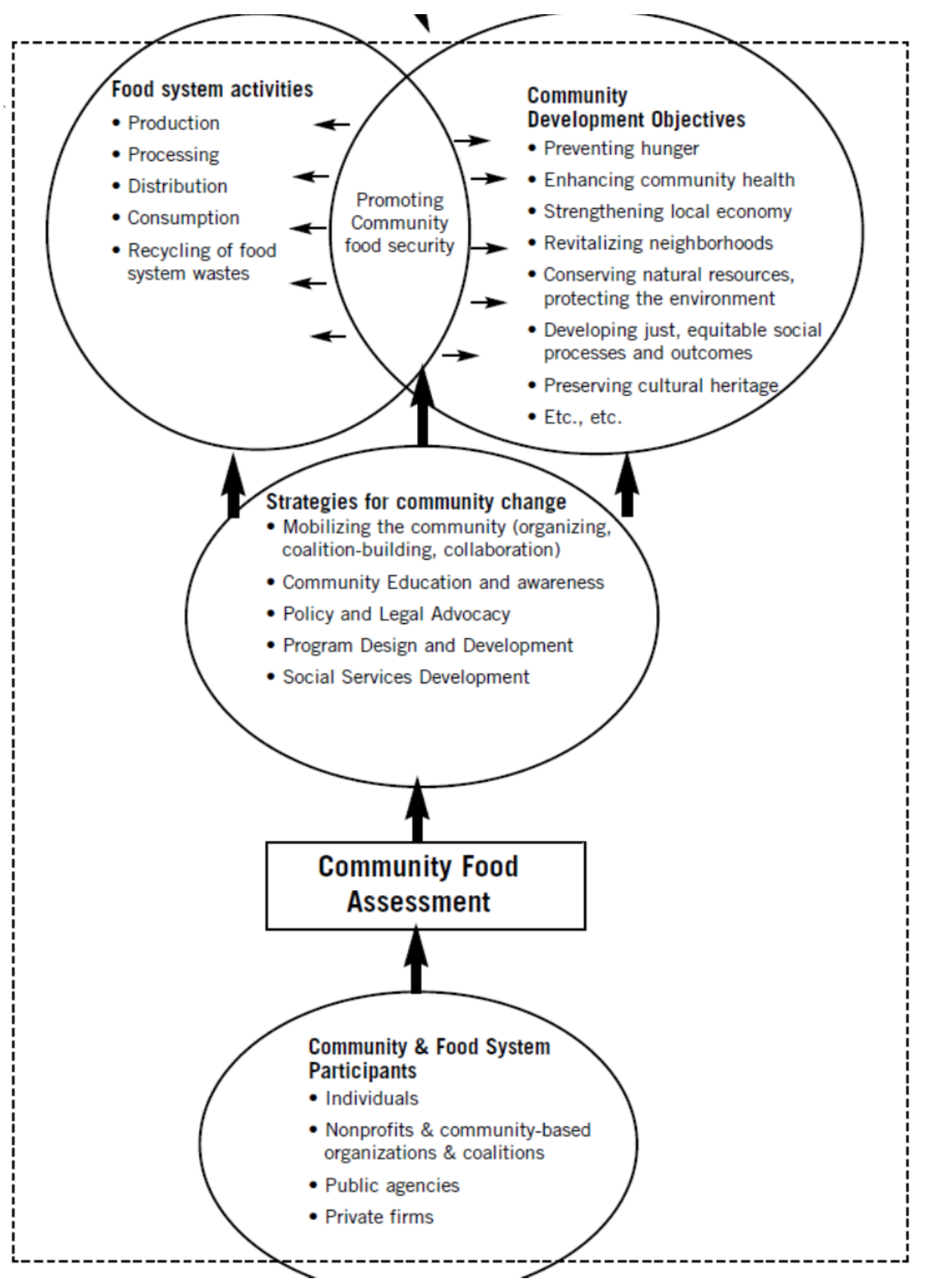

Figure 2 - CFA Model, Pothukuchi et al. (2002) 


\section{Research Problem}

A major limitation in knowledge about CFAs is the dearth of empirical studies of their effectiveness in achieving their goals within the communities they seek to improve. Once the CFA's concluding report has been written and its recommendations delivered to the community, little evidence follows that this work has led to decreased overall need (i.e. reduced FI) within that same community. One reason for this has been the lack of local-level data on household or individual FI.

The USDA developed the household food security (HFS) survey in 1995, establishing it as the standard measure of food insecurity (FI) for the nation and individual states ever since. Since 1998 the USDA has been collecting and publishing, with the help of the U.S Census Bureau, data on household food security (HFS) for the nation and for the individual states (Coleman-Jensen et al., 2016; Nord \& ColemanJensen, 2009). For example, the USDA reported that $12.7 \%$ of all Americans were foodinsecure at the household level in 2015 which indicates that $87.3 \%$ of Americans were food secure in that same year (Coleman-Jensen et al., 2016). FA began extrapolating localized data on individual FI in 2009 and has been publishing its results for counties and congressional districts via its MMG website since 2011 (FA, 2014). Data have not been published, however, that would allow studies on FI to be conducted at the local community level, such as communities that are smaller than a full county or that do not match the shape of a congressional district. 


\section{Purpose of the Research}

The intention of this dissertation research is to determine whether these community-based participatory research efforts are, in the aggregate, having an impact on improving CFS and in fact reducing FI across their counties. Specifically, this dissertation research examined what happens to the FI of community residents after the CFA is delivered to the community by asking the following research question: Does the CFA positively impact the food-insecure population within two years of the dissemination of its concluding report and recommendations to the community? In other words, given a reasonable amount of time (two years) for the community to develop the CFA's recommended initiatives, has the CFA contributed to an effective reduction in individual FI in the community?

The central hypothesis of this dissertation is that the CFA will improve CFS for all members of the community, particularly the most food insecure among them. The best indicator that improvement has indeed reached the least food secure of the community is to compare the community-level estimates of individual FI across time once the CFA has been concluded.

\section{Research Aims}

This study aims first to develop a better understanding of the types of communities where CFAs have been conducted, in particular those selected for this study. The principal aim of the research is to examine MMG data for communities that completed a CFA so as to determine whether CFAs help reduce individual FI over a twoyear post-CFA period. The specific hypothesis is that communities conducting CFAs 
experience a reduction in individual FI within two years of the dissemination of results and recommendations for community action steps.

A secondary aim of the research is to explore the data to see what it suggests about the characteristics of communities that have demonstrated greater or lesser success following the implementation of a CFA, according to the following parameters: Urban communities versus rural, larger total populations as compared to smaller, communities that are more racially and ethnically diverse, where the incidence of unemployment is higher, where the median household income is lower, where poverty is higher and where the incidence of home ownership is lower. 


\section{CHAPTER II: LITERATURE REVIEW}

\section{a. Food Insecurity}

Shortages or imbalances in farm production, problems with processing and distribution of food, economic constraints or a lack of physical access to sufficient quantities of nutritious food all can have negative and sometimes devastating effects on the health and well-being of people in any part of the world (UN, 2011; 2009; Handler \& Hasenfeld, 2007; Food \& Agriculture Organization [FAO], 2002; Atkins \& Bowler, 2001). The USDA's ERS annually calculates a food insecurity index at the household level and reports that $12.3 \%$ of all U.S. households were food insecure in 2016, down slightly from the previous year's mark of $12.7 \%$, but still higher than the $10-11 \%$ figures that were common prior to the Great Recession of 2007-09 (Coleman-Jensen et al., 2017) (see Figure 3). State-level estimates of FI vary greatly from a low of $8.7 \%$ in Hawaii to a high of $18.7 \%$ in Mississippi with Florida registering a 2016 household FI estimate of 12.0\%. Food-insecure households struggle, at least during some parts of the year, to acquire enough nutritious food to meet the needs of all household members. This can be due to insufficient income or other resources but it also can be attributed to geographical or logistical barriers to access to quality food. 


\section{Estimated total food-insecure individuals in U.S., 1998-2016}

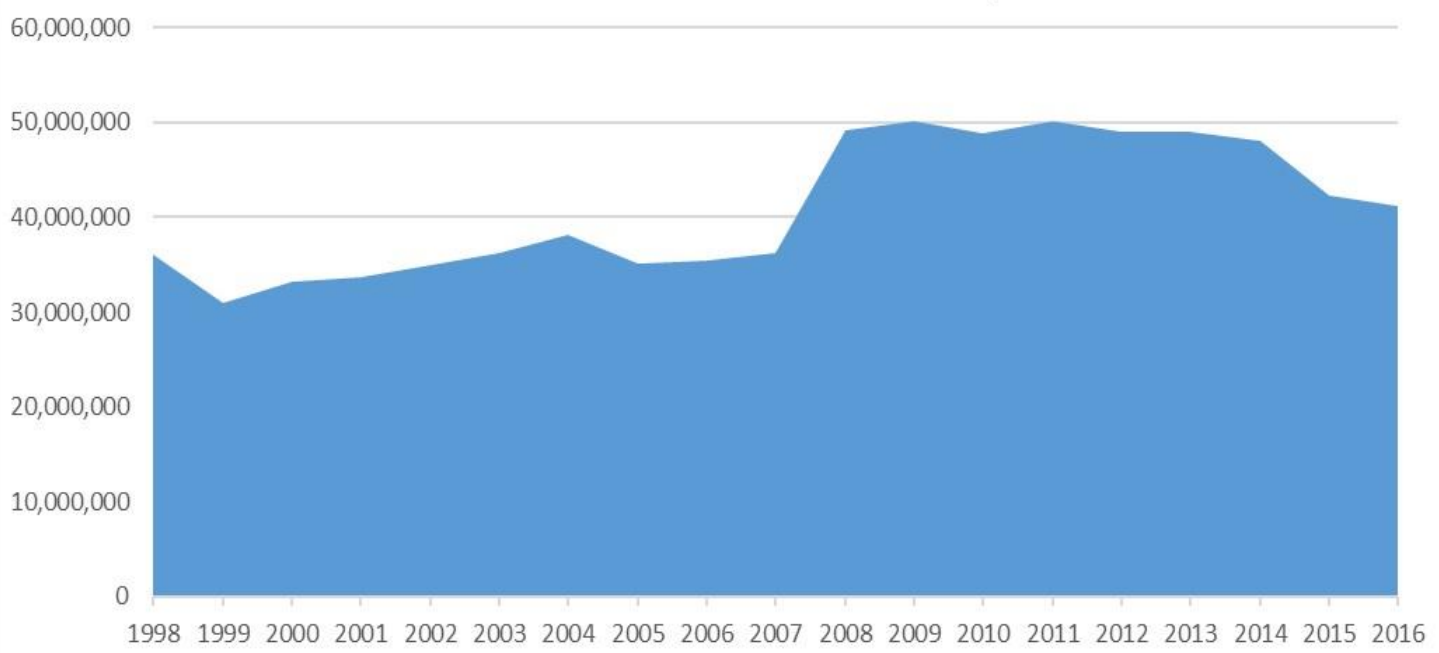

Source: Coleman-Jensen et al., 2017

Figure 3 - Individuals by food security status of household, 1998-2016

When considered at the county level (See Figure 4), as was done in the 2014 MMG study, one can see concentrations of higher FI (indicated by darker shades of green) across the U.S. South, more specifically in the Southeast and the Southwest regions of the country (Gunderson, Satoh, Dewey, Kato, \& Engelhard, 2014). FI affects all races, ethnicities, age groups, and genders; however, it tends to disproportionately affect households with children and particularly those headed by a single parent, or with a Black/African American or Hispanic/Latino head of household. Rural areas, on average, have higher FI scores than cities, and FI is at its lowest in suburban areas (ColemanJensen, et al., 2015). 


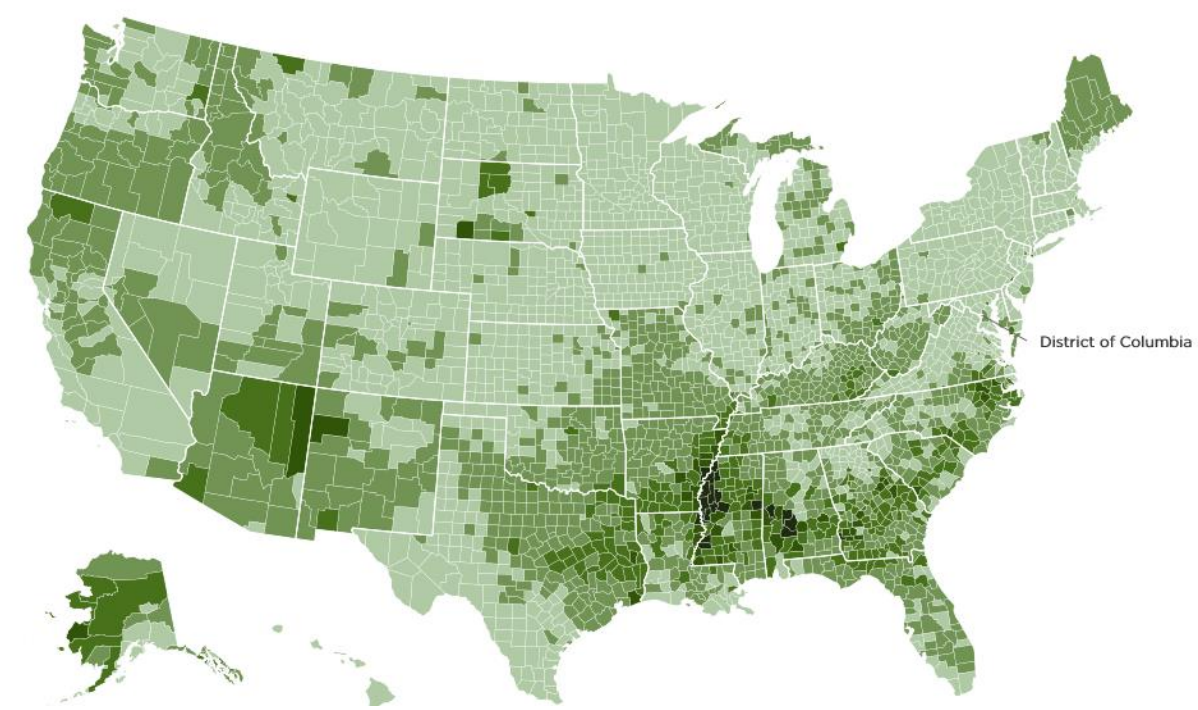

Source: Gunderson et al., 2014

Figure 4 - Food Insecurity at the County Level - 2014

FI is most commonly present in U.S. households that are experiencing poverty, unemployment or underemployment. Also, FI can be found in households not normally considered to be poor or struggling to find adequate employment for their needs.

Circumstances where this can occur might include a temporary loss or reduction in household income (such as loss of rental income or parental support), a change in the composition of the household (e.g., an elderly parent moves in or an unemployed child comes back home) or an unexpected surge in other economic needs that can rob the household of funds that might otherwise be used to purchase food.

Unemployment is still one of the most consistent indicators positively associated with FI (Huang, Kim, \& Birkenmaier, 2016; Nord \& Coleman-Jensen, 2014). In recent years, however, despite consistent reductions in unemployment, poverty and FI continue to test the public safety net. One possible explanation for the continued need for social 
assistance in the face of improving employment statistics is that low-paying jobs accounted for just $21 \%$ of the jobs lost during the economic downturn yet represent $58 \%$ of the jobs gained during the recovery (Rasheed, 2013). Wage growth has consistently lagged behind other indicators in the current nine-year economic expansion, however very recent gains bring encouragement for the future. Eighteen states passed minimum wage increases last year while a large number of corporations have begun passing a share of their 2018 tax gains on to employees in view of the recently-passed reduction in corporate income tax rates (Hahm, 2018; Jones, 2017).

A frequent observation found in the literature is that the U. S. produces enough food to feed every human being living within its borders while at the same time the nation ships enormous quantities of surplus production for food relief overseas (Global Hunger Foundation [GHF], 2011; FAO, 2009; Alexandratos, 1999; Riches, 1997; Hinds, 1990). Today's American farmer is eight times as productive as his/her ancestors of just 100 years ago, producing enough to feed an estimated 155 people compared with just 19 people per farmer in 1920 (Farm Journal Foundation, 2017).

FI is in general caused by poverty and inequality and not because of food shortages (Gimenez, 2014). The problem is one of equitable distribution; the U.S. fails to get sufficient, nutritious food to all those who need it, when they need it. Berg (2008) suggested that FI in America is essentially a political problem; that the U.S. government seems to lack the political will to dedicate adequate public funding to distribute internal food relief more equitably. The problem is more complex than that.

The Agricultural Act of 2014 (also called the U.S. Farm Bill) authorized \$390 billion in spending for the USDA's nutrition and food assistance programs over the law's 
current five-year period from 2014-2018. The bill covers SNAP benefits for as many as 46.9 million people, school lunches for 30.4 million children while 14 million also may get their breakfasts at school, and supplemental food assistance for 8.7 million women and children from WIC (Congressional Budget Office, 2014). Yet, steady increases in funding of these federal food relief programs have done little to stem the tide of FI as can be gleaned from the data displayed in Figure 2.

The federal government's inability to eliminate or even seriously reduce the problem, coupled with peaking issues of poverty and class disparities in recent years, have placed increased pressures on charities to help the food-insecure population find supplemental food (Weinfield et al., 2014). Charitable food distribution has reached an all-time high but, despite yearly increases in donations from non-profits and record tonnage flowing through the food banking networks, household and individual FI continued until recently to hover near all-time high percentages (Coleman-Jensen et al., 2015). The distribution problem is further compounded by lack of accessibility to nutritious foods in neighborhoods designated as food deserts as well as the tendency towards high levels of food waste in American homes and all along the food supply chain (ERS/USDA, 2013a; ERS/USDA, 2011; Albritton, 2009; Berg, 2008; Bhattacharya, Currie, \& Haider, 2004; Eisinger, 1998).

The USDA informs that there are multiple ways to define which areas may be considered food deserts but in their simplest definition they call them "neighborhoods that lack healthy food sources" (2015, para. 1). Ver Ploeg et al. of the USDA's ERS employed a more precise description in their 2012 study declaring the food desert to be a one-half square kilometer tract where at least $40 \%$ of the population earns under $200 \%$ of 
the federal poverty level and lives more than one mile from a supermarket or farmers' market. In the study, based on American Community Survey (ACS) data from 2010, the authors estimated as many as 29.7 million people or nearly $10 \%$ of the U.S. population were living in food deserts in that year.

Another explanation for the U.S.' inability to adequately feed every American is food waste; not all U.S. agricultural production makes its way to household dining tables or other intended uses. The FAO has termed waste the "blind spot in the fight against hunger" (FAO, 2015, p.1). Estimates of just how large American food waste might be are much varied in their conclusions, from $27 \%$ to $40 \%$ is estimated to be lost between its production at the farm and consumption at the dinner table. The clear trend, however, is that the problem has grown progressively worse over the last 25 years (Bloom, 2010; Jones, 2004; Kantor, Lipton, Manchester, \& Oliveira, 1997).

\section{b. Health Consequences of FI}

There are many reasons why a community might want to seek ways to improve its food security; however, none are more important than the overall health of its individual member citizens and families. A study of ER patients treated at four Boston-area hospitals found that food-insecure patients were more likely to complain of chronic physical and mental health problems such as obesity, chronic pain, stomach ulcers, depression, stress, anxiety, PTSD and insomnia. The study further found that the foodinsecure respondents were more likely to avoid or delay purchases of needed medications in favor of providing food for the household, confirming a finding shared by many previous studies (Sullivan, Clark, Pallin, \& Camargo Jr., 2010; Nord, Andrews, \& Carlson, 2008; Chilton \& Booth, 2007). 
The Academy of Nutrition and Dietetics (2013) maintains that dietetic prevention and interventions are keys to reducing the prevalence of many life-threatening chronic diseases including cardiovascular disease, cancer and type 2 diabetes. Dietitians and nutritionists as well as the entire U.S. medical community, led by the Surgeon General, recommend a diet rich in fresh fruits and vegetables and low in processed, high-sodium, sugary foods along with regular exercise as best practices to counter these conditions (OSG, 2001). This can be problematic; however, in that many Americans in urban areas do not have adequate access to either healthy foods or spaces for exercise or both (Friedman, 2008). Low-income and minority neighborhoods are again particularly affected (Larson, Story, \& Nelson, 2009).

\section{Physical Health.}

FI has been established as an important risk factor associated with poor health in adults as well as children (Bitton \& Roth, 2010; Nord, Andrews, \& Carlson, 2008; Stuff, et al., 2004; Vozoris \& Tarasuk, 2003). FI has been associated with poor nutrition which can lead to difficulties in health maintenance as well as psychological problems (Holben, 2010). FI can lead to hunger and, at an extreme, to life-ending starvation. At least five million children die in the world each year from starvation or health conditions directly related to FI. On the other hand, death attributed to hunger in the U.S. is so rare that such a statistic is not calculated (Albritton, 2009; Bickel, Nord, Price, Hamilton, \& Cook, 2000).

FI has been identified as a significant risk factor in malnutrition which can lead to obesity (Tanumihardjo et al., 2007; Townsend, Peerson, Love, Achterberg, \& Murphy, 2001; Dietz, 1995). Obesity, in turn, is a risk factor for a variety of other health problems 
including type 2 diabetes (Naukkarinen, Rissanen, Kaprio, \& Pietiläinen, 2011; Egger \& Dixon, 2009). Malnutrition includes both under-nutrition and over-nutrition with the latter known to be the most common contributor to conditions of overweight and obesity which are further discussed below (Kotz, 1971). The CDC (2015) cautions that for children the association of FI to undernutrition can additionally lead to impaired cognitive development.

Overweight and obesity. Numerous studies have reported that FI is positively associated with overweight and obesity (Adams, Grummer-Strawn, \& Chavez, 2003; Dietz, 1995; Townsend et al., 2001). One retrospective study of adults in the Hartford, Connecticut area found that food-insecure adults were nearly 2.5 times more likely to be obese as those who were food secure (Martin \& Ferris, 2007).

Current patterns of child and adolescent obesity result in part from regular consumption of foods poor in nutrients. Reasons for this consumption pattern include a lack of personal resources at home to buy higher-quality foods, residence in a food desert without the use of a motorized vehicle, nutrient-poor foods being served in schools, and the marketing messages of companies that produce high-calorie, low-nutrient foods such as so-called "fast foods," snacks, soft drinks and candies (Brownell, Schwartz, Puhl, Henderson, \& Harris, 2009).

Obesity and overweight are together considered to be a serious and growing health problem in the United States, growing in severity since 1980 (Trust for America's Health, 2013; The Obesity Society, 2012). They have long been declared leading health indicators by the OSG and a major health challenge by the National Heart, Lung and Blood Institute (NHLBI) of the NIH (NHLBI, 1998; OSG, 2001). Specifically, the 
NHLBI identified obesity as "a serious health condition that leads to increased morbidity and mortality" (NHLBI, 1998, p. 6).

National Health and Nutrition Examination Surveys (NHANES) data from 20112014 estimated that over one third (36.5\%) of the U.S. population was obese (Ogden, Carroll, Fryar, \& Flegal, 2015). That latest study, which compared the most current data with that collected from each of the previous biennial NHANES surveys, confirmed that obesity continues its steady increase in the U.S., up about $20 \%$ from $30.5 \%$ as established in the first survey taken in 1999-2000.

The OSG declared in 2001 that obesity had reached the level of a national epidemic, alarmed at the increase from an estimated average of just $15 \%$ for the period from 1960-1980 (Adams et al., 2003; OSG, 2001). Women, minorities, the elderly, the poor and the less-educated have shown greater tendencies toward overweight and obesity than their demographic counterparts (Ogden at al., 2015; OSG, 2011; Pietrobelli, 2005; Adams, et al., 2003; Townsend, et al., 2001). NHANES data for 2011-2012 indicated that obesity prevalence was $47.8 \%$ among non-Hispanic black adults and $42.5 \%$ among Hispanic adults, significantly higher than the overall average of $34.5 \%$ and the nonHispanic white rate of 32.6\% for the same period (Ogden, Carroll, Kit, \& Flegal, 2013b). Although childhood obesity rates are much lower than the overall adult numbers they have grown at a higher rate, having more than tripled since 1980 (Lavizzo-Mourey, 2009; Marder \& Chang, 2006). The NHANES data from 2011-2012 showed an estimated $17.0 \%$ of American children and adolescents (ages 2-19) to be obese (Ogden, Carroll, Kit, \& Flegal, 2013a). The rates were higher for Hispanic children (20.2\%) and for Non-Hispanic Blacks (22.4\%). 
Levi and associates (Levi, Segal, St. Laurent, Lang \& Rayburn, 2012) project a grim public health scenario for the year 2030 suggesting that if the current trends continue the U.S. will be facing a nationwide obesity rate of $44 \%$, with some states as high as $60 \%$. Obesity is a significant cause of death in adults and is in turn an important risk factor for serious diseases like diabetes, heart disease, some cancers, and arthritis which may in turn lead to death (CDC, 2010). The Obesity Society declared that the condition has replaced smoking as the number one preventable cause of death in adults (2012).

Diabetes mellitus. Studies have revealed links between FI and diabetes in women (Seligman, Bindman, Vittinghoff, Kanaya, \& Kushel, 2007), in children (Marjerrison, Cummings, Glanville, Kirk, \& Ledwell, 2011), among the elderly (Homenko, Morin, Eimicke, Teresi, \& Weinstock, 2010), within the Latino community (Fitzgerald, HromiFiedler, Segura-Pérez, \& Pérez-Escamilla, 2011; Kollannoor-Samuel, Wagner, Damio, Segura-Pérez, \& Chhabra, 2011), among Canadians (Gucciardi, Vogt, DeMelo, \& Stewart, 2009; Maddigan, Feeny, Majumdar, Farris, \& Johnson, 2006), among AfricanAmericans (CDC, 2014) and among lower-income populations (Seligman, et al., 2011, Vijayaraghavan, Jacobs, Seligman, \& Fernandez, 2011; Seligman, Davis, Schillinger, \& Wolf, 2010).

The CDC reported in 2014 that as many as 29.1 million Americans have diabetes with more than one quarter of those cases either unknown or undiagnosed. Type 2 diabetes, although more prevalent in adults, is increasingly being diagnosed in children and adolescents and particularly among minorities including African-Americans, Hispanics/Latinos, American Indians, Asians, and Pacific Islanders (CDC, 2014). 
The American Diabetes Association recommends as preventive measures maintaining a healthful diet, regular exercise and keeping one's weight under control (2015). Seligman and associates (2010) suggested that FI can be a risk factor for diabetes in that those so affected tend to eat less balanced and less nutritious food. An additional risk was found by Seligman, Jacobs, López, Tschann and Fernandez whose 2011 study revealed that FI can also make managing type 2 diabetes more difficult for those that already have the disease.

\section{Mental Health.}

FI has been found in the U.S., Canada and other developed countries to have an adverse effect as well on one's mental health as in, for example, depression, anxiety and cognitive issues (Muldoon, Duff, Fielden, \& Anema, 2013; Holben, 2010; Stuff J. E., et al., 2004; Vozoris \& Tarasuk, 2003; Olson, 1999). Substance Abuse and Mental Health Services Administration (SAMHSA) literature includes FI on a list of community factors that can affect mental health (2013).

Cognition. FI has been linked to problems with cognition, academic performance and psychosocial development among school children (Howard, 2010; Alaimo et al., 2001). Bronte-Tinkew, Zaslow, Capps, Horowitz \& McNamara (2007) reported that even the mildest form of FI can be associated with poor cognitive, social, and emotional development of children younger than 3 years. Howard (2010) found that FI at home correlates negatively with children's classroom behavior. The study revealed that FI can affect interpersonal relations, self-control exhibited by control of their temper, respecting the property rights of others and accepting others' ideas. 
Polivy (1996) suggested that restrictive food intake can often lead to binge eating when access to food is temporarily regained. Too frequently such binge eating is of nonnutritious foods in a poorly-balanced intake devoid of dietetic planning. Polivy found that such inconsistency in diet can lead to cognitive disruption and distraction while the individual is focused on eating.

Depression and Anxiety. Research has shown that FI can be related to depression, anxiety, and suicidal ideation among adolescents and adults (Zaslow, 2009; Rose-Jacobs et al., 2009; Casey, Goolsby, \& Berkowitz, 2004; Seifert, Heflin, Corcoran, \& Williams, 2001). FI has been further linked to depression among caregivers in families with children (Melchior, et al., 2009). A broad study of mothers of three-year-old children found the incidence of either a major depressive episode or anxiety disorder was significantly higher among food-insecure mothers (30.3\%) and their children than among their food-secure counterparts (16.9\%) in the cohort (Whitaker, Phillips, \& Orzol, 2006).

\section{c. Previous CFA Reviews}

The authors of a 2004 CFA done in Missoula County, Montana estimated that only about 15 CFAs had been conducted prior to that year (Jacobson \& Hassanein, 2004). That same year a review of nine CFAs was written by an urban planning researcher from Wayne State University including her own community-involved assessment for the city of Detroit, Michigan (Pothukuchi, 2004). In her review, Pothukuchi focused on the CFA somewhat narrowly from her physical-planning point of view, arguing for the value of the CFA for city, county and regional planners. The author concluded that "CFAs are, at their root, planning activities. Regardless of the background of CFA implementers, 
planners could serve as able partners in CFAs and in the actions that follow from assessments" (2004, p. 373).

Finding no more contemporary assessment of CFAs, I conducted an extensive search that uncovered over 100 CFAs that had been conducted in U.S. communities since 2004, the year of the Pothukuchi review. From that large group of studies I selected seven CFAs to represent a geographically and demographically-diverse cross-section of the extant research with which to conduct a more current review (Buschman, 2016). I found that these seven assessments had much in common from a wide perspective including the following specific similarities: They all broadly followed the procedures recommended for such studies by the USDA's Cohen (2002), and by Pothukuchi et al. (2002), customizing them to suit their geographical situations, populations, needs and budgets as these authors suggested they should do. Without exception, all seven CFAs applied the recommended community-based participatory research (CBPR) method to seek community-involved solutions to food issues. Without omission, all seven CFAs brought together a diverse group of stakeholders from the community and kept them focused on the research at hand. While all seven CFAs in the review employed a mixedmethod strategy, the only common methods within those strategies were the use of CBPR, the use of secondary data from a variety of sources, and the employment of a survey questionnaire. Some qualitative methods used by some but not all seven communities included personal interviews, focus groups, and town hall meetings.

The seven CFAs each concluded their efforts with a report of their findings. The reports all made key recommendations on next steps to be taken to improve food security for their communities. On rare occasion a community actually had launched an initiative 
in advance of the final reports to their communities. More frequently, however, the recommendations were left as action steps to be carried out by the community going forward.

The recommendation that a Food Policy Council (FPC) be established was the key conclusion reached by all seven of the reviewed CFAs. Six of the seven communities did act on that recommendation and created their own FPCs. The only community among the seven that did not create its own FPC was that of Southwest Baltimore, Maryland. The community was actually the first of eight neighborhood CFAs conducted in the City of Baltimore by the Johns Hopkins Center for a Livable Future (CLF). Once the CLF had concluded all eight Baltimore CFAs an FPC was then established for the entire City of Baltimore (Baltimore City Food Policy Task Force, 2009; CLF, 2015).

Apart from the above-mentioned similarities, the seven CFAs in my review presented little else in common. In fact, I purposefully selected these seven for their diversity: First, they were geographically diverse; three of the assessments were conducted in communities west of the Mississippi River, two were from the Midwest and two from the East Coast. Second, they were diverse in size; four were realized in smaller communities that had fewer than 100,000 inhabitants while three were done in larger cities or counties with populations of more than a quarter-million. The communities under study occupied physical areas ranging from just 10 sq. mi. to more than 2,500 sq. mi. Third, they were diverse in the scope of their research; five looked beyond the boundaries of their neighborhoods, cities or counties to review the agricultural production and/or food processing capabilities in adjacent rural areas while two limited their efforts 
to studying just the distribution and consumption of food within the community (Buschman, 2016).

In terms of political geography, the studies represented two neighborhoods, one association of neighborhoods, two cities, one county and one city/county unified administrative district. In terms of demography two of the communities housed an overwhelmingly-white majority while five had substantial minority populations in excess of $30 \%$; two sizeable African-American constituencies, two with considerable Latino/Hispanic populations and one with a large number $(>30 \%)$ of both AfricanAmerican and Latino/Hispanic individuals. In terms of FI, household FI numbers ranged from a low of $14 \%$ to a high of $31 \%$, indeed a wide range. It should be noted that all the communities had FI levels above their respective state's average.

Outputs in the form of recommended action steps, and impacts which start with the implementation of those steps, were equally varied. These ranged from just two steps that were immediately implemented in the Argentine neighborhood of Kansas City, Kansas, to as many as thirty-six steps recommended for action in Nashville/Davidson County, Tennessee.

The most important common step taken to ensure long-range impacts was clearly the formation of an FPC which, as mentioned earlier, was recommended by all CFAs reviewed. The most disturbing commonality, however, was the lack of any clear, measurable outcomes, beyond the number of implemented action steps, in any of the CFAs reviewed. This major shortcoming will be discussed more fully below. 
Table 1 - Selected demographic data and other key indicators from seven reviewed CFAs

\begin{tabular}{|c|c|c|c|c|c|c|c|c|c|c|c|c|}
\hline \multirow[t]{2}{*}{ CFA title, author, year } & \multirow[t]{2}{*}{ Community } & \multirow{2}{*}{$\begin{array}{l}\text { Populatio } \\
\text { n }\end{array}$} & \multirow{2}{*}{$\begin{array}{l}\text { Area } \\
\text { (Sq.Mi. } \\
\text { ) }\end{array}$} & \multicolumn{3}{|c|}{ Food insecurity } & \multicolumn{6}{|c|}{ Race \& ethnicity* } \\
\hline & & & & Local & State & U.S. & EA & AA & $\mathrm{L} / \mathrm{H}$ & $A / P$ & NF & $\mathrm{M} / \mathrm{O}$ \\
\hline $\begin{array}{l}\text { "Missoula County Community Food } \\
\text { Assessment" (Jacobson \& Hassanein, } \\
\text { 2004) }\end{array}$ & $\begin{array}{l}\text { Missoula } \\
\text { County, MT }\end{array}$ & 95,802 & 2593 & $31 \%$ & $17 \%$ & $12 \%$ & $94 \%$ & $0 \%$ & $1 \%$ & $1 \%$ & $2 \%$ & $1 \%$ \\
\hline $\begin{array}{l}\text { "Transforming the Oakland Food } \\
\text { System: A Plan for Action" (Unger \& } \\
\text { Wooten, 2006) }\end{array}$ & $\begin{array}{l}\text { City of } \\
\text { Oakland, CA }\end{array}$ & 390,865 & 56 & $29 \%$ & $15 \%$ & $11 \%$ & $36 \%$ & $\begin{array}{r}27 \\
\%\end{array}$ & $24 \%$ & $\begin{array}{r}17 \\
\%\end{array}$ & $1 \%$ & $0 \%$ \\
\hline $\begin{array}{l}\text { "Understanding and Addressing Food } \\
\text { Security in Southwest Baltimore" } \\
\text { (Palmer, Smith, Haering \& McKenzie, } \\
\text { 2009) }\end{array}$ & $\begin{array}{l}\text { Neighborhood } \\
\text { of Southwest } \\
\text { Baltimore, MD }\end{array}$ & 71,009 & 10 & $18 \%$ & $13 \%$ & $11 \%$ & $25 \%$ & $\begin{array}{r}71 \\
\%\end{array}$ & $0 \%$ & $1 \%$ & $1 \%$ & $0 \%$ \\
\hline $\begin{array}{l}\text { "Central Texas Food Assessment" } \\
\text { (Banks, 2011) }\end{array}$ & $\begin{array}{l}\text { Neighborhood } \\
\text { of East Austin, } \\
\text { TX }\end{array}$ & 271,590 & 298 & $18 \%{ }^{i}$ & $17 \%$ & $15 \%$ & $0 \%$ & $\begin{array}{r}32 \\
\%\end{array}$ & $62 \%$ & $0 \%$ & $0 \%$ & $0 \%$ \\
\hline $\begin{array}{l}\text { "Cultivating an Agenda for Change: A } \\
\text { Dynamic Model for Community Food } \\
\text { Assessments" (Johnson et al., 2011) }\end{array}$ & $\begin{array}{l}\text { City of } \\
\text { Nashville } \\
\text { /Davidson } \\
\text { County, TN }\end{array}$ & 603,527 & 475 & $14 \%$ & $17 \%$ & $15 \%$ & $66 \%$ & $\begin{array}{r}28 \\
\%\end{array}$ & $10 \%$ & $3 \%$ & $0 \%$ & $3 \%$ \\
\hline $\begin{array}{l}\text { "Argentine Healthy Foods Access } \\
\text { Initiative" (Mabachi \& Kimminau, 2012) }\end{array}$ & $\begin{array}{l}\text { Neighborhood } \\
\text { of Argentine, } \\
\text { Kansas City, KS }\end{array}$ & 10,468 & 4 & $21 \%$ & $15 \%$ & $15 \%$ & $63 \%$ & $\begin{array}{r}13 \\
\%\end{array}$ & $39 \%$ & $2 \%$ & $1 \%$ & $5 \%$ \\
\hline $\begin{array}{l}\text { "Community Food Assessment" } \\
\text { (GFCLA, 2013) }\end{array}$ & $\begin{array}{l}\text { City of } \\
\text { Lewiston, ME }\end{array}$ & 36,592 & 34 & $\begin{array}{c}25.2 \\
\%\end{array}$ & $15 \%$ & $14 \%$ & $87 \%$ & $8 \%$ & $2 \%$ & $1 \%$ & $1 \%$ & $3 \%$ \\
\hline
\end{tabular}

${ }^{*}$ Race/Ethnicity: EA=White or European American; AA=African American; L/H=Latino/Hispanic; NA=Native American; A/P=Asian/Pacific Islander; $\mathrm{M} / \mathrm{O}=$ Mixed/Other

Sources: The CFA documents themselves + U.S. Census Bureau and USDA reports for the years in which the CFAs are dated. 


\section{d. Conceptual approaches and methods of previous researchers}

CFS is both a methodology and a goal; the method being a multi-disciplinary local systems approach to FI and the goal being to eliminate the problem of FI at the community level so that it cannot or at least should not exist at the individual or household level (Winne, Joseph, \& Fisher, 1997). CFS combines efforts in such diverse fields as urban planning, community development, sustainable and urban agriculture, nutrition, coalition-building and policy work, as well as traditional anti-hunger advocacy as it endeavors to identify and correct gaps and deficiencies in the overall community food system. CFS takes a prevention-oriented, public health approach, in contrast with the traditional methods to reduce FI (e.g. SNAP, WIC) that primarily address the symptoms of the problem.

According to the USDA, CFS is "a prevention-oriented concept that supports the development and enhancement of sustainable, community-based strategies" (ColemanJensen, Gregory, \& Rabbitt, 2015). Examples of these strategies include the development of community gardens in previously-vacant lots, policy change on zoning regulations where urban agriculture (UA) may have previously been a code violation, communitysupported agriculture (CSA) agreements with nearby farms, purchase of special trucks for mobile food pantries and other methods designed to deliver fresh produce, dairy and other nutritious foods to inner-city food deserts, locations where FI is often at its worst.

CFS may also include local support and outreach for traditional federal programs such as the Supplemental Nutrition Assistance Program (SNAP), the Special Supplemental Nutrition Program for Women, Infants and Children (WIC) and the many 
school-based meal, snack and nutrition education programs. Finally, CFS may support the flow of local food to those in need through traditional community-level efforts such as food pantries and emergency (soup) kitchens. To incentivize and guide the development of these local strategies, the USDA launched the CFS Initiative which established three strategic goals to: a) strengthen food systems at the local level; b) decrease overall need (i.e., reduce FI); and c) improve human nutrition (Kantor, 1999).

Mark Winne (2003), a pioneer proponent of CFS and co-founder of the Community Food Security Coalition (CFSC), explained that CFS evolved as a combined anti-hunger and community development movement. The establishment of the influential coalition followed closely on the heels of one of the earliest and still one of the most comprehensive examples of collaborative community food system research. "Seeds of Change: Strategies for Food Security for the Inner City" was a groundbreaking project conducted between 1992 and 1993 in South Central Los Angeles by urban planning researchers from UCLA, in cooperation with the non-profit Southern California Interfaith Hunger Coalition. The extensive final report documented the Los Angeles food system from the unique perspective of a lower-income, inner-city neighborhood and its many food-insecure residents. The collaborative research effort contributed to the establishment of the Community Food Projects Competitive Grant Program, funded by the 1996 Farm Bill through the USDA's National Institute of Food and Agriculture (NIFA). It led as well as to the first National Food Security Conference, held at UCLA in 1997 (Gottlieb \& Fisher, 1996; Pothukuchi et al., 2002).

The CFS movement developed rapidly. As researchers, practitioners and policymakers gathered more expertise on the topic they saw that the mere fact of having a 
good food supply in a particular community did not mean that all of its residents would logically have access to that supply (Anderson \& Cook, 1999; Lutz, Swisher, \& Brennan, 2007). Gottlieb and Fisher (1996), who guided the original research project at UCLA and participated in much of what followed in that community, suggested parallels between CFS and the environmental (green) movement in that both fostered community empowerment, both were concerned with equity and sustainability, and both encouraged expanding the agendas of other related movements including each other's.

Food systems and nutrition researchers Hamm and Bellows (2003) put forward an oft-cited definition for CFS as existing when "all community residents obtain a safe, culturally-acceptable, nutritionally-adequate diet through a sustainable food system that maximizes community self-reliance, social justice and democratic decision-making" ( $\mathrm{p}$. 37). Pothukuchi and colleagues (Pothukuchi, 2004; Pothukuchi et al., 2002) said that the movement's intentions were to eliminate hunger and FI and to support access to food as a basic human right. They stressed that food availability and access was in this case a community-level construct.

Jacobson and Hassanein (2004) suggested that while most hunger intervention models were based on either household or individual FI, they themselves advocated for a large, community-level macro-intervention based on CFS. The CFS model, they explained, considers a community's strengths and assets to meet its own needs as it seeks to improve the actual food security of the entire community. This view is not unlike that taken by others; CFAs conducted by urban planners, agriculturalists or other disciplines do typically take the strengths-based approach and look for gaps in the food system. Jacobson and Hassanein's innovation was to merge the CFA's macro view of developing 
their community's food system with their knowledge of food access from the individual or household point of view.

The CFSC's Cohen, author of the USDA's Community Food Security Assessment Toolkit, wrote that CFS can be viewed as an expansion of individual and household FI and that the ultimate goal is food security for all people in the community. Cohen (2002) suggested that the principal question to be asked by an assessment should be whether or not HFS is a significant problem in the community. While cautioning that HFS is not the same as CFS, Cohen argued that in this sense when the HFS measure is used in a representative survey of the community, it can provide a solidly-quantified "bottom-line" indicator of the state of food security within the community, as directly experienced by community members. This makes the HFS survey a strong tool for community needs assessment and monitoring of the community's progress over time in reducing the prevalence of food insecurity.

Gottlieb and Fisher (1996) contended that CFS is measured by determining a community's ability to provide adequate and appropriate food for the entire community. Banks (2011) suggested that one way to determine the successful progress of a community towards full CFS is to evaluate initiatives that may have been funded by the USDA Community Food Projects Competitive Grants Program since those are, by definition, directly tied to the concept. Banks added, however, that while this method may help to evaluate the impact of these steps towards CFS, it does not provide an actual measure of CFS. 
The USDA's position on CFS is that there is no universally-accepted definition for the construct but then propose that a community could be considered food insecure if any of the following conditions exist (Coleman-Jensen et al., 2015; Cohen, 2002):

- $\quad$ Shortage of sources where community members may purchase foods

- $\quad$ Available sources are not accessible for all community members

- $\quad$ Food available at those sources is limited in quantity or variety

- $\quad$ Food available at those sources is not affordable for all community members

- $\quad$ Food assistance resources are insufficient for lower-income members

- $\quad$ No local food production sources exist

- $\quad$ Local food is produced but not made available to the community

By these standards, it is unlikely that most American communities will ever be able to find themselves fully food secure. Cohen (2002) confirmed the notion that CFS is an elusive goal and suggested that communities will find that their relative CFS exists somewhere on a scale ranging from food insecure to food secure but never at either absolute end of that scale.

Once stakeholders agree that their community has a problem with FI and decide that they want to work towards attaining the goal of CFS, how do they determine their relative baseline and how will they measure their progress? Cohen gives clear instructions on how to establish a baseline by conducting a representative survey using the HFS measure and citing the Guide to Measuring Household Food Security by Bickel et al. (2000). Pothukuchi and colleagues were far less precise, however, emphasizing instead the recruitment of a wide variety of planning committee stakeholders and then 
selecting goals from among their interests. FI figured as the eighth of ten bullet points on their "Sample List of Basic Community Indicators That May be Addressed by Your Assessment" (Pothukuchi et al., 2002, p.53).

On the other hand, there is much agreement among these authors that the first step in evaluating CFS should be to initiate a comprehensive, systems-view assessment known as the community food security assessment (CFA), or the sometimes-broader food systems assessment (FSA). Distinctions between these terms have been rather blurry in the literature; therefore, for the purposes of this study, unless otherwise mentioned or labeled, any of these variously-named assessments shall be referred to generally as a CFA.

Cohen explains the term CFA as a "collection of various types of data to provide answers to questions about the ability of existing community resources to provide sufficient and nutritionally sound amounts of culturally acceptable foods to households in the community (2002, p. 8). Pothukuchi and associates, in their "Guide to Community Food Assessment” defined the CFA as "... a collaborative and participatory process that systematically examines a broad range of community food issues and assets, so as to inform change actions to make the community more food secure" (2002, p. 11).

McCullum, Desjardins, Kraak, Ladipo, and Costello (2005) proposed that three stages of evidence-based strategies, along a continuum that stretches from short-term to long-term, should be employed to establish CFS. The first stage would be of activities and strategies that represent small changes to the existing food system with data collected to support further changes to the system in the ensuing two stages. The second stage should be the transition of the structure of the food system to support needed long-range 
changes. Examples given included the reduction from wide reliance on the local food bank toward the establishment of community gardens and community-supported agriculture. The third stage would involve the larger redesign of the food system through such actions as changing land-use policies to allow for the development of urban agriculture and providing incentives to attract supermarkets and other food distribution entities to low-income neighborhoods as well as to enhance food access and good nutrition. While McCullum et al. do suggest that data collection, monitoring, and evaluation are important and should be done for all of the activities at each of the stages, they do not provide any suggestion of how it can be determined when CFS can or will finally be attained, nor how to measure for it.

McCullum et al.'s three stages of CFS strategies and activities describe the process which frequently begins with a CFA and often includes the establishment of a food policy council (FPC), alternatively called a community food council, community food coalition or food security council. For the purposes of this dissertation, only the term FPC shall be used, except in those instances that refer to proper names.

Some communities, as noted earlier in this paper, moved first to establish their FPC and then realized the need for a comprehensive CFA study as an initial, albeit complex, action step (Burgan \& Winne, 2012). Whichever the order, it is clear that the CFA and the FPC are both highly important steps to the long-term goal of CFS in any community. The CFA is a baseline-producing snapshot in time, guiding a process that will uncover gaps and weaknesses in the food environment as well as identifying community assets and strengths. While the CFA will synthesize this information and point the community in certain directions, it does have an end point. That is perhaps why 
one of the most common recommendations made by any CFA process is that an FPC should be established to carry the process forward and activate other important recommendations.

\section{e. Strengths and limitations of the findings in the literature}

The literature on FI, CFS and related concepts covers a broad multi-disciplinary swath of research and policy topics from food-production-related items in agriculture and sustainability, to post-consumption, public health outcome issues including childhood obesity and adult type 2 diabetes. Literature in nutrition education, community development and urban planning dominates when FI is studied at the community level.

Finding methods that can successfully nurture CFS is a challenging task due to the many varied interests that diverse stakeholders bring to bear on the issue. Doing so from the perspective of social work can be more daunting still, given that many of those interests are of a for-profit nature. The CFA appears to be the one intervention comprehensive enough to consider as well as bring together these many diverse interests. Presentations of empirical data on CFAs have been very few and largely qualitative in nature. This dissertation examines, with currently-available quantitative data, whether or not communities engaging in CFAs are finding success in their goal of reducing FI by increasing public access to adequate quantities of nutritious food.

\section{f. Theoretical Models}

Efforts to assist the food insecure have existed for millennia as evidenced in the scriptures of some of the world's great religions including the Hindu Urpanisads (Taittiriyaka Upanishad, 3rd Valli, 10th Anuvaka:I), the Judaic Tanakh or Written Torah (Mishlei 22:9; Deuteronomy 24:19), the Christian New Testament ( Isa 14:30; Isa 49:10; 
Matthew 25:35, KJV) and the Muslim Qu'ran (Abu-Dawud:2824; Al-Baqara 2:215). In fact, some of the earliest-known community soup kitchens (tamhui) were developed in Ancient Israel, during the period of the Second Temple, in response to the increased needs of an expanding population (Robbins, 2006).

The concepts of FI and CFS, however, are modern ones and not well understood by academics due in part to their newness and in part to the fact that they are not squarely situated in any one discipline of study. FI and CFS have been studied by agriculturalists, by urban planners, by nutritionists, by medical practitioners and, to a lesser extent by academics from other disciplines including social work.

There are equally as many theoretical frameworks from which one can look at the multidisciplinary, multifaceted CFS movement. Writing about community interventions in general, author Reisch (2012, p. 83) has suggested: "Because community intervention serves multiple functions, the role of theory in its development is complex and often synthetic...informed by a wide range of theories." From the social work perspective, theories of social justice and person-in-environment systems are the most applicable to CFS.

Social Justice. The widely-cited definition for CFS by Hamm and Bellows' (2003, p. 37) specifically includes a food system that “...maximizes self-reliance, social justice and democratic decision-making" that will ensure that everyone in the community will be able to maintain a nutritious, safe and culturally- acceptable diet. Historically in the U.S. there have been many food-related movements of social justice including the United Farm Workers' grape boycotts of the 1960s, the "5 cents for fairness" initiative in favor of strawberry workers' wages in the 1990s, the USA Domestic Fair Trade Working 
Group in the 2000s, and the current CFS movement that emphasizes local food production, processing, distribution, and consumption (Hinrichs \& Allen, 2008; Domestic Fair Trade Working Group, 2006; United Farm Workers, 1996).

Much of the direction of the CFA and its many working parts can be seen clearly from this social justice perspective. In Missoula, Montana, Jacobson and Hassanein (2004) relied on the work of Pothukuchi and colleagues (2002) to guide their CBPR effort within what they termed a social justice framework for community social work practice. In that work, the CFA was described as a method for exploring a community's food system in terms of its "food security, social justice and other community values" (Pothukuchi et al., 2002, p. 12). Finn and Jacobson called this their Just Practice Framework, one that makes "power, inequality, and transformational possibilities the foci of concern, thus offering a theoretical bridge between the concept of social justice and the practice of social work" (Finn \& Jacobson, 2003, p. 69).

The social justice foundation of CFS underscores the importance of having social work professionals involved in the CFA process. Social justice is a system of values for social workers which "underscores everything they do" [National Association of Social Workers (NASW), 2016, para. 3]. CFS is well-aligned with the NASW approach to social justice which suggests that the social work professional will generally work to address structural issues and suggest changes that will help clients gain access to the many resources and services they may need, not only to survive but to fully develop and thrive as human beings. Social workers also will seek to empower their clients (whether 
individuals, families, groups or communities) over time to manage their own acquisition of these resources and services.

Systems. Systems and ecological theories and perspectives have guided social work for decades and broadly reside behind the CFS movement as well. Ericksen (2008) declared that to fully understand the many interdependent factors and multi-level dynamics of a community food system and its relative food security one must take a systems approach. The systemic nature of the CFA has been noted throughout this paper and even those CFAs that espouse a primary framework of social justice have recognized the absolute importance of working towards that goal from a systems perspective.

Midgley (2006) wrote about how the development of general systems theory (GST), first articulated by Bogdanov in 1910 and later by von Bertalanffy in 1956 and 1968, has made possible the use of a wider, richer array of methods, both quantitative and qualitative, with which to assess complex problems and evaluate their often-complex solutions. GST expands the view from that of a single stakeholder to allow a multiplicity of stakeholder perspectives. Midgley suggested that differing stakeholders explore their necessary interconnections and system boundaries from their unique perspectives on an issue.

Elaborating on the need for a systems perspective in food issues, Conner and Levine (2006) offered a framework for the construct they termed Community-based Food Systems depicted in Figure 5 below as a series of interacting causal loops. From their view, change is not always good for all stakeholders; each item in the model may affect other related items and/or the entire community food system itself, either positively or 
negatively. Those whose interests are not benefitted by the proposed change, they suggested, will oppose and even fight vigorously against the effort to build a community food system. This aspect of the issue further underscores the importance of the macrooriented social worker's active involvement in the CFA process to lend support to agencies of social welfare dealing with the food-insecure and to advocate for the foodinsecure population, particularly when there is disagreement of other interests that may affect it.

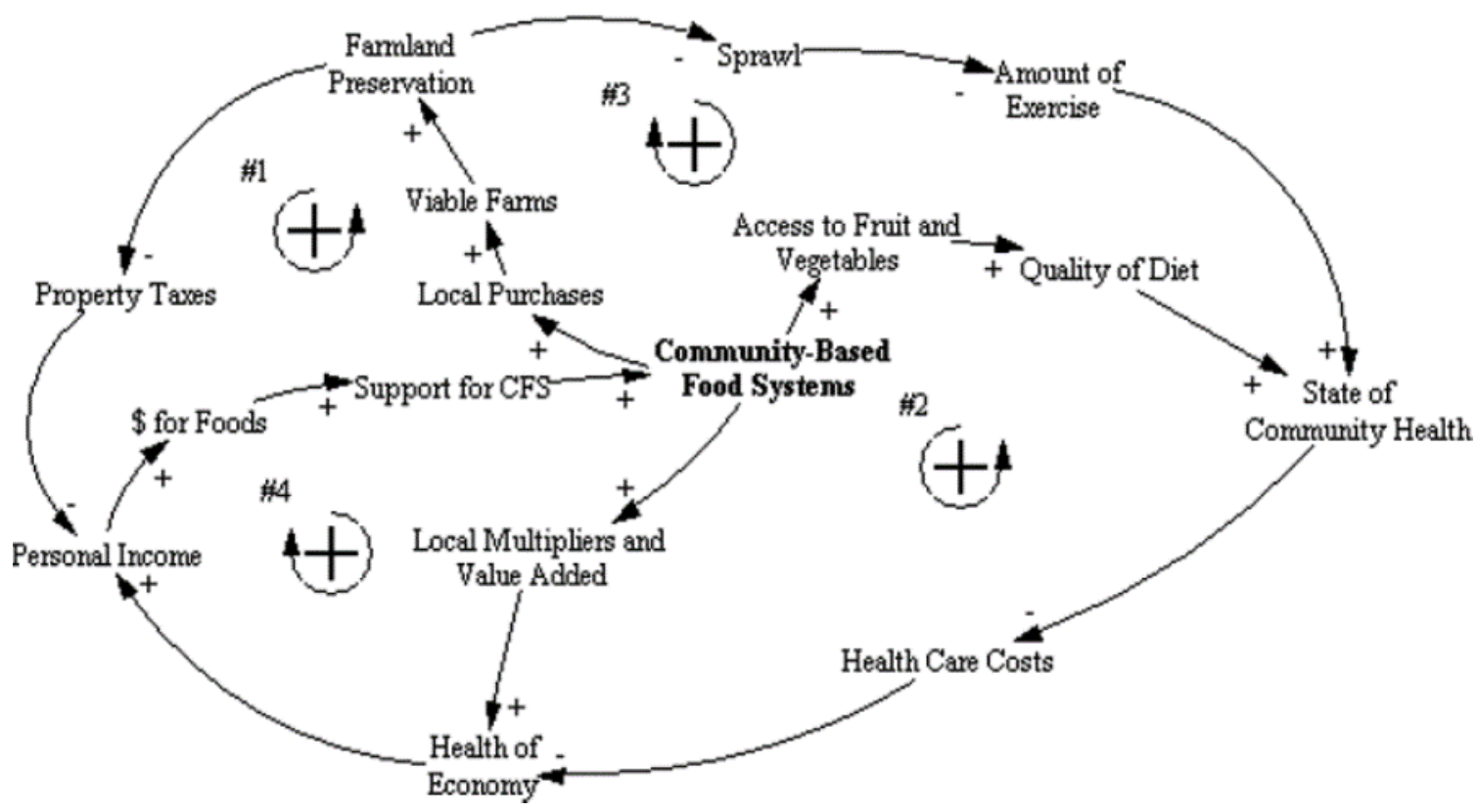

Source: Conner \& Levine (2006)

Figure 5 - Conner \& Levine’s Community-based Food Systems model

In developing their model, the authors considered the standard five food-system sectors of production, processing, distribution, consumption and waste recovery, and the extent to which each is interconnected and based within the same community (geographic in scope). Community-wide engagement and integration of the various stakeholders 
including local government, community leaders, food producers, distributors and sellers is needed in order to move forward toward community-wide solutions. Of greatest interest from a social justice perspective is loop \#2 that demonstrates how CFS and community-based food systems support, in succession, access to fresh fruits and vegetables, quality of diet and the state of community health. Loop \#4 is also important to social work in that it supports improvements in the local economy which can lower unemployment and poverty, two of the strongest indicators for food insecurity.

Banks (2011), in writing the CFA for East Austin, Texas, observed that the CFS movement had arisen to systematically address injustices in access to the basic human necessity of food. The author further suggested that the entire CFS movement effectively “...approaches issues of food security at each stage of the life cycle of food to ensure that each stage is sustainable, socially just, and equitable," adding that her study used the framework to “...challenge traditional notions of food security by critically examining the economic, social and environmental barriers to food equity in Austin" (Banks, 2011, p. vi).

Palmer, Smith, Haering and McKenzie (2009) in their S.W. Baltimore CFA specifically cited the Hamm and Bellows definition for CFS as they designed their study to focus on food access in those underserved Baltimore neighborhoods. Good Food Lewiston-Auburn (GFLA) focused on the social justice of food access, understanding the systemic nature of the food environment and the CFA that would capture its essence and point out its faults. They set the stage for their Lewiston, Maine, CFA with the words: "We are working to create a system where accessing the ideal good food is possible for 
everyone. However, we know that this is not the current reality; for some people the priority is just getting enough to eat" (GFLA, 2013, p. 1).

Mabachi and Kimminau's (2012) Argentine, Kansas CFA sought to improve “a historically underserved, low-income, urban, community of color that has poor access to healthy foods" (p. 280). The Argentine CFA was also, according to these authors, “...an example of how partnering with academic and other institutions to develop creative and strategic solutions to food access problems can be successful and rewarding” (p. 286). Oakland's CFA process involved multiple phases but the central HOPE Collaborative involved "A wide spectrum of organizations, institutions and community residents ... transforming the food and fitness environments in neighborhoods suffering the most from health disparities ... in Oakland's most vulnerable neighborhoods ..." (Hope Collaborative, 2009, p. 5).

The Nashville CFA's perspective was somewhat different from the other six CFAs reviewed. They called it a Food Systems Assessment and approached the project from a systems-view on public health and the role of food within that system. Nashville conducted this CFA as a component of a broader community health assessment process and worked from a rather different set of guidelines. Some consideration was given to the consumption phase as the study looked at the number of residents receiving food assistance through WIC, SNAP and school-meal benefits. However, the report was more essentially focused on the production and distribution of food looking at size and distribution of farms, food processing, markets, community gardens, and the like. 
Although Nashville's approach was slightly different, it is nonetheless clear that each of the seven CFAs followed a community-wide systems approach, integrating a variety of local stakeholders in their CBPR process. There is some divergence, however, on how many stakeholders were involved in each, and even on how many of the five food sectors were included. As stated earlier, five of the seven studies looked beyond the borders of the defined areas of study to consider the agricultural production and/or food processing capabilities of adjacent rural areas, leaving that two did not. While all of them assessed and made recommendations for improving food access through sectors of distribution and consumption, the majority did not consider the food waste sector at all. These variations are true to the flexibility and adaptability of the Cohen/Pothukuchi models and their recommendations that they be modified to suit the diverse needs, budgets and populations of each community.

A consistent and prominent recommendation of all seven CFA-producing communities was the implementation of a perpetually-funded FPC to continue work on the community's food system once the CFA had concluded its findings. The FPC's role is to fill in the gaps identified in the food system by the CFA, to find any support (e.g. financial, legislative, popular, etc.) that may be needed to implement the recommended action steps and to ensure that they get carried out. There can be a time lag between the end of the CFA process and the beginning of the FPC's work, however it was common to see committee members who had helped design or carry out the actual CFA give continuity to the process by staying on as FPC council members. In the case of Nashville, their FPC was established prior to the conducting of the CFA. However, in the 
other six cases it was the CFA that made the determination that an FPC would be needed going forward. 


\section{CHAPTER III: METHODS}

\section{a. Research Design}

Previous attempts to measure any successes or failures of CFAs were limited to evaluating individual community food initiatives that had been recommended and developed either during the assessment period or after the delivery of the CFA report. Moreover, such attempts typically did not include individual action steps that were not part of USDA or other sponsor-funded food programs that required post-hoc evaluation and reporting. They largely failed to consider government planning initiatives with their potential for longer-term change. The majority of the evaluations also failed to consider the cumulative effect of the action steps and initiatives on the overall CFS of the community. This research endeavored, therefore, to evaluate the aggregate effect of the entire CFA process on the measured individual FI of the community's members at two years following the dissemination of its concluding report and recommendations to the community.

\section{Sample Population.}

Approximately 120 CFAs were found to have been conducted in U.S.

neighborhoods, cities, counties and multi-county regions from the late 1990s through 2014. Multi-year FI data were only obtainable, however, at the county, congressionaldistrict and state levels. This limitation in the available data precluded any type of longitudinal study for CFAs performed in communities that did not conform to those specific political boundaries. No CFAs were identified to have been conducted at the level of congressional district, and only one was found at the state level. The data 
revealed, however, that more than one-half of all identified CFAs, had been done by or for U.S. counties.

From this sample frame, sixty-six U.S. counties were identified as having been the subjects of CFAs conducted at the county or multiple-county levels between the years 2009-2012, thus forming the research sample that could fit the available county-level data across multiple years. This highly-representative sampling afforded the possibility of two-year longitudinal comparisons for those studies that were concluded in 2009 (allowing the comparison of data from 2009-2011), in 2010 (comparing data from 20102012), in 2011 (comparing data from 2011-2013) and in 2012 (comparing data from 2012-2014).

\section{b. Measures}

MMG County-level FI measure. This is a continuous variable of percentage of individual FI by year, by county. Access to MMG project data was granted by FA, the sponsor of the study, for the purposes of this research. Data was subsequently provided by FA on individual FI at the state, county and congressional district levels for the years 2009 - 2014 (Gunderson, Dewey, Crumbaugh, Kato, \& Engelhard, 2016). County-level FI scores were then culled for the 66 counties in the sample for the baseline year of each CFA's publication (BL) and for the same counties two years later $(\mathrm{BL}+2)$. The $\mathrm{BL}+2$

measure of two years post-test was selected because the preponderance of CFA literature indicated that most communities had either initiated, planned to initiate or recommended implementation of initiatives in the first year or two following the CFA's report to the community. 
Community Size Measure. This measure is a dichotomous variable allowing for the comparison of larger communities with total populations over 50,000 inhabitants, versus smaller communities under 50,000. Population data were retrieved from ACS 5year estimates on Demographic and Housing Estimates. The 5-year estimates were selected ending in the year the CFA was published and disseminated. For example: 2007 - 2011 5-year estimates were used for a CFA published in 2011. The binary variable was established using a threshold of 50,000 inhabitants, the same threshold used to define a Metropolitan Statistical Area (MSA) from a micropolitan or rural area. (ACS, 2016a).

Unemployment. For this measure a continuous variable was employed from the U.S. Bureau of Labor Statistics' (USBLS) Labor Force Data by County, 2009 - 2014 Annual Averages. These data were retrieved on 8/17/2017 from Local Area Unemployment Statistics of the USBLS (USBLS, 2017).

Home Ownership. For this measure a continuous variable was employed from the U.S. Census Bureaus' American Community Survey (ACS) Housing Tenure - Owner Occupied, 2009 - 2014 Annual Averages. These data were retrieved on 8/17/2017 from Selected Housing Characteristics, ACS 5-Year Estimates (ACS, 2016b).

Median Household Income. For this measure a continuous variable was employed from ACS'Median Household Income (US\$). These data were retrieved on 8/17/2017 from Selected Economic Characteristics, ACS 5-yr Estimates (ACS, 2016c).

Poverty. For this measure a continuous variable was employed from ACS' Percentage of Families \& People Whose Income in Past 12 Months is Below the Poverty Level - All People (\%). These data were retrieved on 8/17/2017 from Selected Economic Characteristics, ACS 5-yr Estimates (ACS, 2016c). 
Urban/Rural. For this measure a continuous variable was employed using the U.S. Census Bureau's County Rurality Level: 2010 (U.S. Census, 2018). This document provided percentages of county populations living in rural areas as of the 2010 Census. Counties with less than 50 percent of the population living in rural areas are considered mostly urban and over 50 percent are considered mostly rural. A county with zero percent rurality would be completely urban and 100 percent would be classified as completely rural.

Diversity index. For this measure a continuous variable was employed using the diversity index created by the US2010 Project of the Russell Sage Foundation and American Communities Project of Brown University (Lee, Iceland \& Sharp, 2012). In this index a score of 100 represents perfectly-balanced diversity (equal parts of five different ethnic and racial groupings) while a score of zero means that the entirety of the county's residents is categorized within a single ethnic or racial group.

Community size, poverty, home ownership, median household income and poverty were taken from five-year averages provided by the ACS of the U.S. Census Bureau. MMG authors indicated that they preferred to use the five-year averages instead of one-year data to avoid problems caused by yearly fluctuations that might make countylevel data less stable. Unemployment statistics were factored in from yearly data provided by the BLS. While underemployment also is considered to influence FI, data on underemployment is not available at the county level.

Reliability of the U.S. Census Bureau's CPS data on FI is based on 20 years of consistency and annual sample sizes of 50,000, always surveyed in the month of December. Reliability of ACS data has the advantage of being produced yearly as 
compared to the decennial U.S. Census. The annual survey covers one in 40 U.S. households.

\section{c. Data Management}

The secondary data used in this study involved no contact with human subjects, and there were no characteristics within the data that could be used to identify any individuals. No sensitive information was stored that would require deliberate security measures.

\section{d. Analytic Strategy}

\section{Research Strategy and Design.}

To address Aim 1, geographical mapping of counties producing CFAs was undertaken using Excel PowerMaps and ARC GIS. Referring to the model in Figure 5, the study looked at community size, rurality, and regional location for potential relationships with communities that were able to reduce individual FI over the two years post-CFA.

For Aims 2 and 3, quantitative analysis of secondary data estimates of individual FI were performed using SPSS software. County-level data were input according to the above-described measures and sources for the 66 communities. One-way repeated measures of Analysis of Variance (ANOVA) were conducted to examine the change in Food Insecurity (FI) starting with the baseline year and again after two years (i.e., FI baseline +1 and FI baseline+2). Data were analyzed for each community that coincided with the year of the dissemination of the CFA to its community as a baseline, and for two

years following those efforts (e.g. Larimer County, CO: 2011-2013). In order to examine 
the moderation effects for Aim 3, split-plot (or mixed-design) ANOVA interaction analyses were conducted.

There were no missing data in the dataset. One outlier was found in the subject of Marin County, California which had a median income of over $\$ 90,000$ for its baseline year, well above the standard for identifying outliers at 1.5 times the inter-quartile range. The outlier was removed from the sample, and the study continued with the remaining 65 counties, an adjustment to $\mathrm{n}=65$ for Aim 3 analyses.

Ethical Considerations. MMG provided the secondary data used in this study with their written permission for use in this research. MMG research was conducted using the USDA, U.S. Census Bureau and USBLS national data sets and involved no contact with human subjects. This research, in turn, used only aforementioned secondary data sources. The dissertation research required no contact with human subjects, and there were no characteristics within the data that could be used to identify any individuals. 


\section{CHAPTER IV: RESULTS}

This chapter presents the findings of the analyses performed on quantitative data obtained on 66 U.S. counties where CFAs were concluded between the years 2009 and 2012.

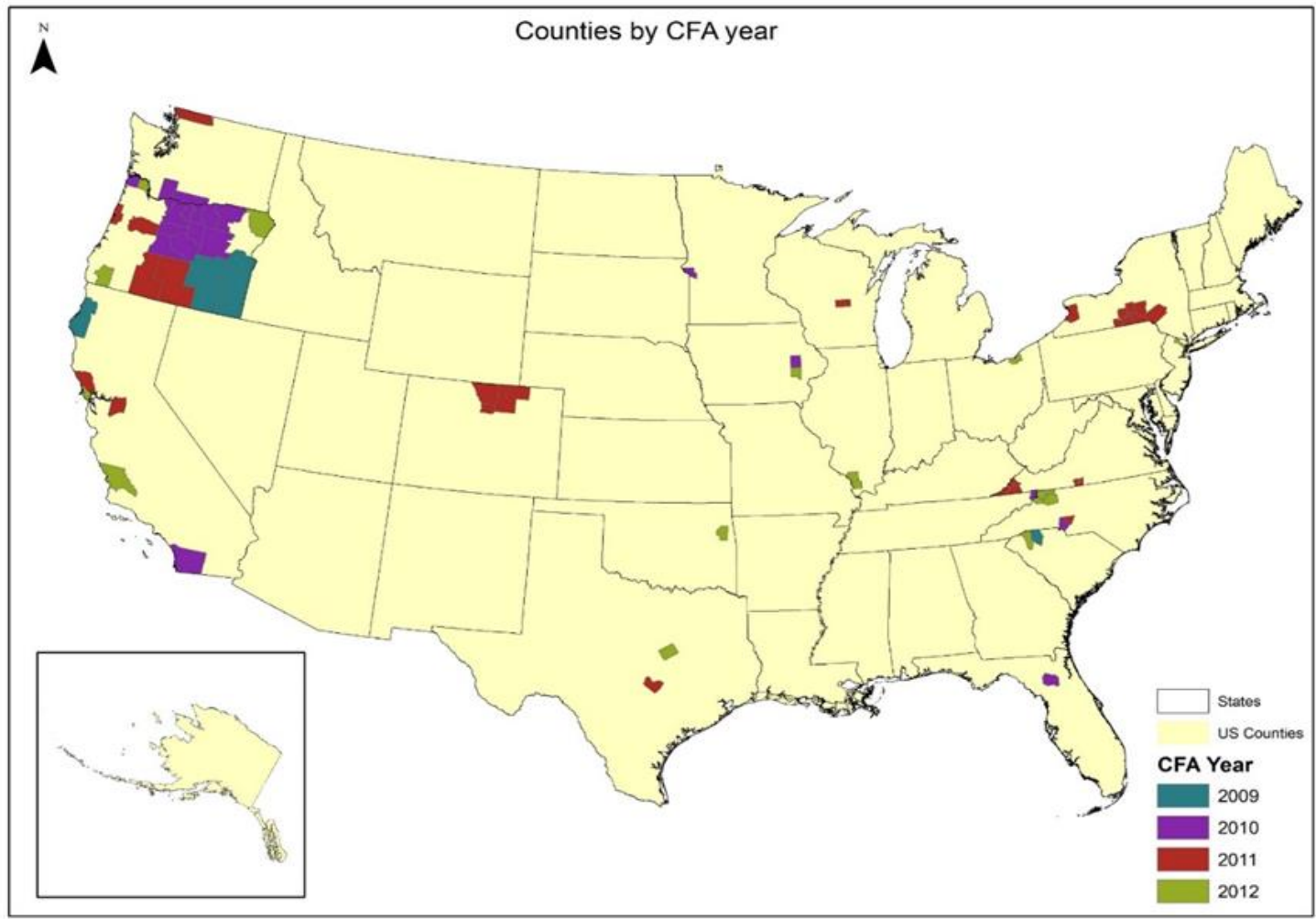

Figure 6 - U.S. Counties in the study by CFA year

\section{a. Aim 1}

Mapping of the county-level data provided spatial information not readily visible from the raw quantitative information displayed on the Excel spreadsheet or in SPSS. Four distinct groupings emerged from this analysis, those being the largely-rural counties of Oregon (21), Colorado (3), western portions of North Carolina, South Carolina and Virginia (12), and Upstate New York (9). Altogether these groupings account for about 
two-thirds of the 66 counties in the study. With the exception of the Northern Colorado and the Upstate New York groupings, the CFAs were completed in different years as may be seen in Figure 6.

It was further observed from the mapping that only sixteen (16) or less than $25 \%$ of the studies were conducted in the southern U.S. where MMG data have shown that county-level food insecurity is more prevalent than in much of the rest of the country. No county-level CFAs were found during the period of the study for the states of Alabama, Alaska, Arizona, Arkansas, Georgia, Idaho, Kentucky, Maine, Mississippi, Missouri, New Mexico and West Virginia. According to MMG county-level data for 2014, these states exhibited large concentrations of higher-than-average county-level FI as may be seen in the MMG map of all U.S. counties, see Figure 7. 


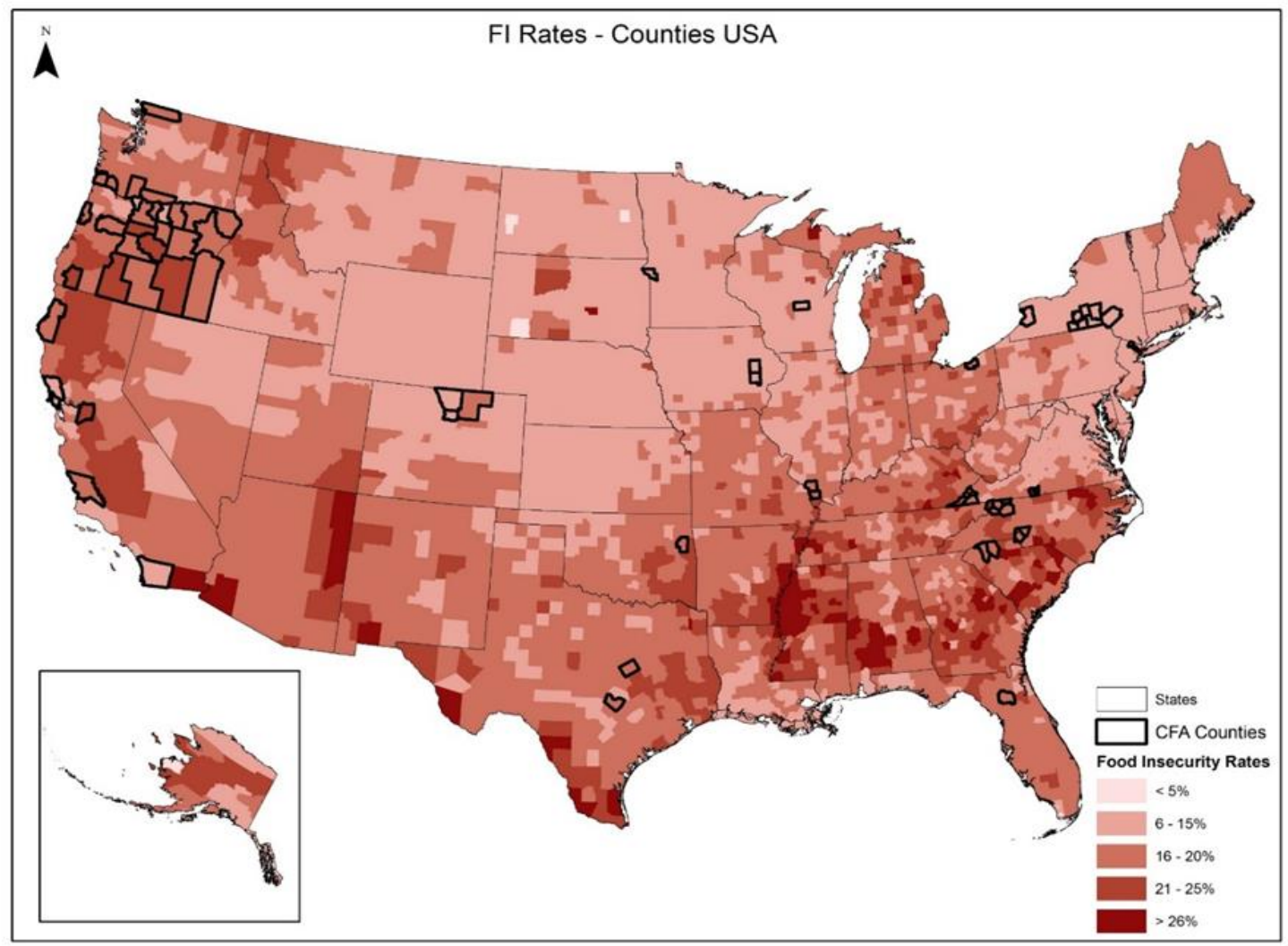

Figure 7 - U.S. counties in the study over county-level FI rates nationwide

One final view of the data in mapping provides an image of where the differences in FI from the baseline (BL) year of the study to post-test two years later $(B L+2)$. This view can be seen in Figure 8 with raised bars and darker hues denoting the greater positive change in county-level FI from pre-test $(\mathrm{BL})$ to post-test $(\mathrm{BL}+2)$. Where there was no change or negative change, the counties appear flat with no bars visible. 


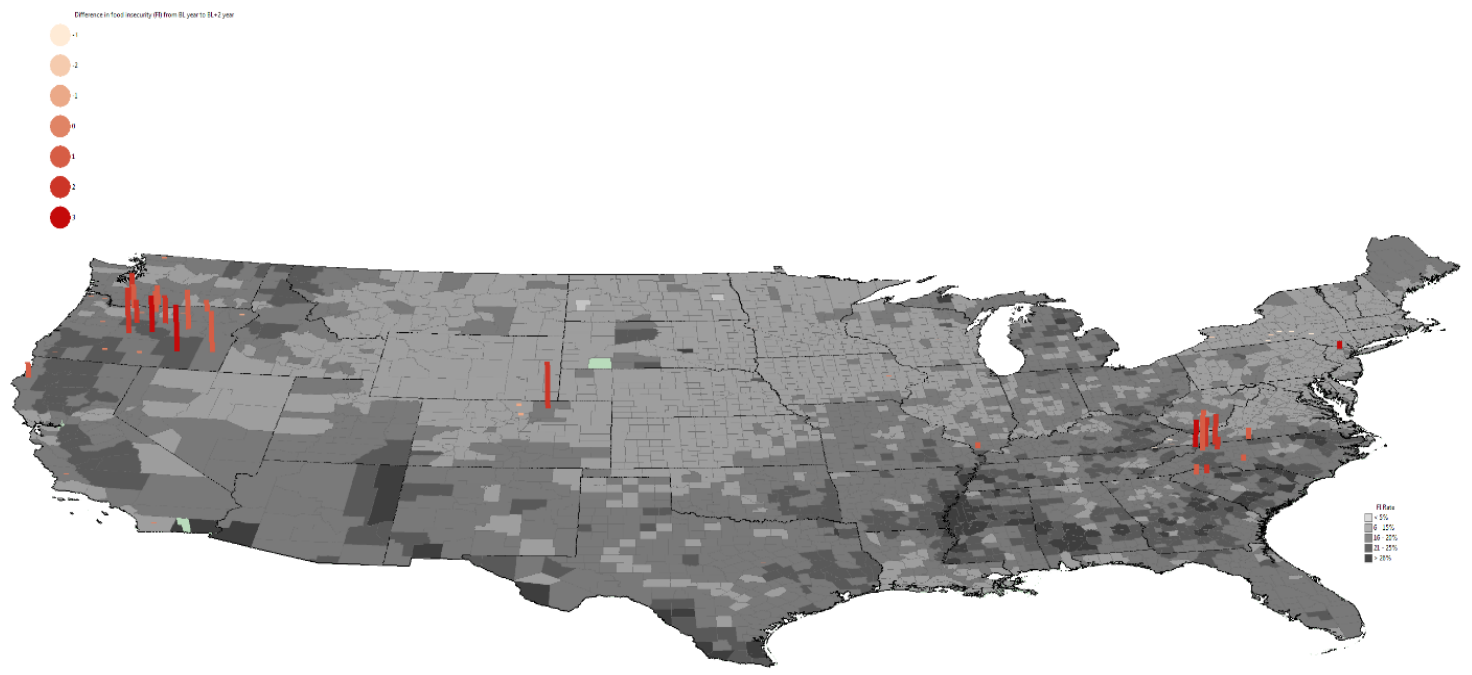

Figure 8 - Percentage difference between pre-test and post-test for county-level CFAs in the study.

\section{b. $\operatorname{Aim} 2$}

Quantitative MMG data for U.S. counties were examined in SPSS statistical software to explore trends in change between the baseline year of the CFA conclusion (BL) and two years post-CFA (BL+2). Sixty-six (66) counties were identified as having produced a CFA that would fit the available MMG county-level data.

Frequencies were run in SPSS to find that a majority (56.9\%) of 37 counties did experience a decrease in the county-level individual food insecurity index (FI) over the period from baseline (BL) to baseline plus two years $(B L+2)$. Twenty-five counties $(38.5 \%)$ experienced an increase in FI while the remaining three counties $(4.6 \%)$ saw no change across the two-year time frame. 
Repeated measures of ANOVA were employed to compare the BL with BL+2 observed measures of FI for each of the 66 counties. The main effect was found to be not statistically significant at $\mathrm{F}+.245$ (1), $\mathrm{p}>.05$.

\section{c. $\operatorname{Aim} 3$}

Following the proposed model I explored the relationships between all parameters (unemployment, diversity, poverty, median income, total population, home ownership and percentage of rurality) and the difference in community FI $(B L-[B L+2])$. All seven parameters were included as covariates and regressed on the change in county-level FI. Statistical significance was not found between the FI change and any of the covariates, with the exception of unemployment. The study did find a significant difference in levels of unemployment between communities that experienced decreases in individual FI, and those that experienced increases, at the county level, at $\beta=.387$ (.067), $\mathrm{p}<.01$. The unemployment rate was found to be significantly high among the counties that showed an increase in the difference in FI compared with those that showed a decrease in the difference in FI, from BL to BL+2. In other words, for each percentage point increase in unemployment the study found an increase of .387 across the two-year time period of the study.

Although the other six parameters showed no significant impact on the change in FI, they still did influence the change in some way. Table 2 provides the means and standard deviations for each of the parameters when FI change has been categorized according to those 25 counties that experienced an increase in FI over the period, those 37 that experienced a decrease and the three that showed no change. 
In Table 2 it is clear that, besides the parameter of unemployment, diversity, poverty, median income and community size showed higher means for the 37 counties that decreased overall FI (improved) than it did for the 25 counties that increased overall FI (where it got worse).

\begin{tabular}{|l|r|r|r|}
\hline \multicolumn{1}{|c|}{ Parameters } & & $\begin{array}{r}\text { Individual Food } \\
\text { Insecurity \% (FI) at } \\
\text { County Level }\end{array}$ & \\
\hline & Increased & \multicolumn{1}{c|}{ Decreased } & \multicolumn{1}{c|}{ No Change } \\
\hline Unemployment Mean (SD) & $.08(.014)$ & $.108(.03)$ & $.096(.01)$ \\
\hline Diversity Mean (SD) & $35.44(19.88)$ & $40.51(16.56)$ & $33.0(9.54)$ \\
\hline Poverty Mean (SD) & $.17(.054)$ & $.18(.06)$ & $.14(.01)$ \\
\hline Median income Mean (SD) & $44877.9(8180.37)$ & $44975.7(9555.00)$ & $45718.67(4954.87)$ \\
\hline \% Rural Mean (SD) & $.49(.33)$ & $.47(.30)$ & $.52(.33)$ \\
\hline $\begin{array}{l}\text { Community size Mean } \\
\text { (SD) }\end{array}$ & $.44(.33)$ & $.46(.51)$ & $.67(.58)$ \\
\hline $\begin{array}{l}\text { Home ownership Mean } \\
\text { (SD) }\end{array}$ & $.68(.76)$ & $.67(.07)$ & $.69(.11)$ \\
\hline & & & \\
\hline
\end{tabular}

Table 2 - Parameter means and standard deviations for counties that increased, decreased or saw no change in FI from pre-test to post-test.

While this dissertation research did not find significance in the reduction of community-level FI where CFAs in the sample were conducted (Aim 1), it did find a significant relationship between an increase in unemployment in the community, and the reduction in FI over the test - post-test period. Further, a review of means and standard deviations of the remaining parameters showed better results, on average, for the 37 counties in the study that did experience an improvement (reduction) in community food insecurity (Aim 2). GIS mapping provided additional insight into specific grouping of CFAs where they appeared to be more effective and pointed out the dearth of CFA studies in the regions of the country most beset by FI. 


\section{CHAPTER V: DISCUSSION}

\section{a. Findings}

This dissertation research sought to answer the question: Does the CFA positively impact the food-insecure population within two years of the dissemination of its report and recommendations to the community? The results of this research were equivocal. The finding of no significance in the relationship between pre-test baseline county-level FI (BL) and post-test baseline plus two years county-level FI (BL+2) suggests that the CFAs in this study, in general, did not significantly affect overall FI of the county.

The second, clarifying part of the main research question is worth reiterating: “Given a reasonable amount of time (two years) for the community to develop the CFA's recommended initiatives, has the CFA contributed to an effective reduction in individual FI in the community?" It is possible that two years is an insufficient period of time to find a positive overall contribution. Future research should consider longer time periods (e.g., 5 years) between CFA initiation and possible changes in FI.

Unemployment was the single influencing factor, amongst the seven considered by this study, to have demonstrated a significant influence. The literature supports that unemployment and poverty are indeed the two most-influential factors in FI. However, no explanation has been found as to why poverty did not join unemployment as a significant influence on FI.

GIS mapping demonstrated that the CFAs in the study were not conducted in many of the states where county-level FI is most concentrated. Figure 8 further demonstrates that CFAs performed in communities of higher overall FI had more 
success, demonstrating greater amounts of positive change pre and post-CFA. In particular those done in Oregon, Colorado and western Virginia and Carolinas, showed the greatest amount of improvement in overall FI.

Mapping also showed that very few CFAs were attempted in the region sometimes referred to as the "Southern Black Belt" stretching from East Texas to the Carolinas, or in the Hispanic region that runs from Southern California to South-central Texas. It may be that fewer resources were available in these regions for such community-involved initiatives undertaken at the local level; this may have biased results toward reflecting communities where there are greater opportunities to realize this type of intervention.

\section{b. Implications for Social Work Practice}

The social justice foundation of CFS underscores the importance of having members of the social work profession involved in the CFA process. CFAs may be approached from the position of macro social work or social welfare taking care to include all possible stakeholders in the effort; community organizers may be well situated to coordinate and lead effort to improved food access to their entire community. Public policy social workers, administrative, organization or management social workers are also potential leaders of CFA development.

School social workers in systems that have a high participation in school breakfast and school lunch programs understand well that these programs are only helping affected students from Monday through Friday and only when school is in session. Further, they do not address the needs of the household that the child will return to after school. Like 
SNAP, WIC and other nutritional programs, SLP does not address the root of the problem.

Clinical and school social workers often use participation in these programs to assist in their assessments of household and family needs (Martinez \& Kawam, 2014). Expanding the community practice approach to work to improve better awareness, access and funding of these programs can indeed be a critical component of a CFA.

Establishing and improving connections to new and other sources of nourishment can be done through the many other stakeholders in the CFA process.

Without the active participation, if not leadership of community social workers, there is little advocacy for the food-insecure population of the community and the many agencies that serve them including food pantries, soup kitchens and shelters. It is a daunting but necessary task due to the many varied interests and pressures that diverse stakeholders bring to bear on the CFA process, given that many of those interests are of a for-profit nature.

\section{c. Policy Implications}

There is a lack of vision regarding food policy in this country, home of some of the most advanced, large-scale industrial food production on the planet. Massive federal programs disconnect with thousands of local food projects, each with a different method of funding and a different mission, operating in silos much like one would see driving across the heartland. Federal and state-level policy must be brought to bear on ensuring that these types of interventional studies are done in those communities where FI is highest. It has not gone unnoticed in this study that CFAs are for the most part not being done in the areas of highest FI. 
There are now over 250 food policy councils (FPCs) in the U.S., at state, county and mostly local levels. FPCs are highly important to the CFA process but often are constituted after the study has been completed. This can occur where a community is bringing stakeholders to the table for the first time on the issue of food production, distribution and access for all. It may also happen where local government has been absent from the conversation.

Communities intending to conduct CFAs need be cognizant that the project will have limited life and duration without the foundation and perpetuity of an FPC. Local government administrators must be involved insofar as policy changes may be necessary to reduce or eliminate zoning or statutory barriers that may be impeding more efficient production and distribution of nutritious foods in the local community. State-wide FPCs are being formed in many states that can educate local communities on the process, as well as help them find the necessary resources.

The trend is now building for state FPCs to provide such education, resources and networking connections to the many local communities developing their own FPCs and CFAs, no matter the order in which these may come to fruition. These organizations are so relatively new, however, that very little research has been done to analyze their success on any measure.

California established its FPC in 2013 and now has a constituency of 26 community-level FPCs. Colorado created its own in 2015. The Florida Food Policy Council, of which I am a founding board member, had its first full meeting less than a year ago. Kansas does not have a state FPC but the Kansas Alliance for Wellness supports the development of local and regional food policy councils FPCs through grant 
opportunities. The Kentucky Food Policy Network, started in 2015, now has 15 local and regional councils under its guidance. Maine has established its own FPC in 2010, Maryland in 2013, Michigan in 2015 while North Carolina and Ohio started FPCs in 2012.

The Virginia Food Policy Council, established in 2007, has had more time to mature and show others what can be done by concerned and concerted stakeholders. In addition to creating a working group for network development that advises local and regional councils, this organization has several strong initiatives in place including farmto-school projects, farm-to-institution program and a "Buy Fresh, Buy Local" campaign.

\section{d. Study Limitations}

The availability of data limited the research in a number of ways. First, the subcounty-level CFAs could not be included. CFAs conducted in specific neighborhoods or multiple-neighborhood divisions of a city, especially the less-affluent sections, are among the most interesting community studies undertaken. When conducted at these levels there appears to be a greater overall involvement of the community of retailers and consumers. Second, the municipal, city-level CFAs are only included in those cases where the city and county share boundary lines. The earlier-mentioned example of Nashville/Davidson County, Tennessee is such a case. CFAs conducted at this level are typically well funded, often involve sophisticated city planning departments and are frequently among the most elaborate. Third, county-level CFAs frequently include more rural areas in addition to urban areas located within the county. County-level CFAs therefore may tend to bring more farmers and distributors into the research and planning, it also introduces the dynamic of less-populated areas as well as the potential for less 
diversity among residents. Fourth, the county-level CFAs are sometimes conducted in multi-county groupings which have cooperative agreements, share resources and common markets. Such larger-area CFAs may skew results by grouping counties of similar types of food production and distribution infrastructure, or similar demographic make-up. Dissimilarities may also be present in such groupings, particularly where one of the counties may contain an urban area and is surrounded by several counties that are largely suburban or rural.

Additional study limitations include the consideration that currently-available data do not offer the possibility for longer evaluations of FI effects in the communities under study. Also, while the sampling was clearly not a convenience sample, it was not large enough for random sampling which may limit the generalizability of findings. Finally, the relatively small sample size of 65 counties may have limited somewhat the statistical power of the analyses related to Aim 3.

\section{e. Implications for Future Research}

It may be that specific components, the policy changes and food-access initiatives emanating from the CFA, are making a difference in the individual FI of those foodinsecure individuals who are directly affected by the CFA, however this is beyond the scope of this research. The few empirical studies existing on the topic were in fact limited to reviewing individual initiatives, although frequently due to requirements of the grant-making agencies involved and not in consideration of their overall effect on the community. An expansion of this type of research may be required to find more specific effects of the CFA. 
One recommendation would be to consider the totality of the CFA components before drilling down to evaluate the efficacy of each in relation to indices of community FI. Once completed, the research should endeavor to reconnect the successes and failures of those components in their geographical, economic and socio-demographic contexts. Once best practices can be observed in these contexts, the research would serve to inform FPCs and community CFA research going forward.

It may be possible, in future research, that with more than two years of data (including MMG data from 2015 now available, and from 2016 and beyond as it becomes available), that richer data may be obtainable. MMG is an annual and ongoing project therefore each year of data that becomes available will yield more longitudinal data on county-level FI and on the covariate parameters. Expanding the study with additional years of measurement would, without doubt, increase the number of CFAs to be included in a follow-up study, thereby increasing its power.

With regard to Aim 3, which looked at the various parameters of potential influence, only unemployment was found to correlate. Unemployment has been steadily improving in the U.S. since 2009, as has the USDA's index for individual food insecurity. But why then would poverty, the other parameter that the literature confirms to be a prime predictor of FI, not have shown correlation? It may be that poverty is not coincident but rather a lagging indicator unemployment, perhaps a result of long-term unemployment. Poverty may also correlate with underemployment which is not well researched nor understood in relation to FI. In either case, this is the subject of economic analysis and beyond the scope of this dissertation. 
CFAs may do well to include employment-producing initiatives in their strategies. Attracting businesses such as food-processing plants, distribution centers, farmers markets, and supermarkets for food deserts and other economically-depressed areas in the community, may be beneficial in multiple ways. In addition to providing greater accessibility to food in the community, these types of initiatives may also reduce food insecurity by generating employment.

GIS mapping demonstrated that CFAs in the study were not conducted in many states where county-level FI is at its highest concentration. Mapping further showed that very few were attempted in the regions known as the Southern Black Belt stretching from East Texas to the Carolinas, or in the Hispanic regions that runs from Southern California to South-central Texas. It may be that fewer resources are available for such community-involved initiatives undertaken at the local level and results skewed toward a reflection of communities where there are greater opportunities to realize this type of research intervention.

This dissertation research suggests that CFAs have much potential for improving food access in communities nationwide but also that there is a dearth of fundamental research that might establish better guidelines and best practices. The study found some indication that CFAs can be more effective in areas of higher unemployment as well as where FI is higher; it causes us to consider why more CFAs have not been conducted in areas where the problem is greatest. Overall, this dissertation suggests that proper development and structure of state and local level FPCs may lead CFAs to find better structure, funding and best practices to become more effective. 


\section{REFERENCES}

Abbott, C. (2017). So Far, 2018 Farm Bill is 'Stealth Legislation'. Retrieved 2 01, 2018, from Successful Farming: https://www.agriculture.com/news/business/so-far-2018-farm-bill-isstealth-legislation

ACS see: American Community Survey

Academy of Nutrition and Dietetics. (2013). Position Paper: The Role of Nutrition in Health Promotion and Chronic Disease Prevention. Journal of the Academy of Nutrition and Dietetics, 113(7), 972-979.

Adams, E., Grummer-Strawn, L., \& Chavez, G. (2003). Food insecurity is associated with increased risk of obesity in California women. Journal of Nutrition, 133(4),1070-1074.

Alaimo, K., Olson, C., \& Frongillo, E. J. (2001). Food insufficiency and American schoolaged children's cognitive, academic and psychosocial development. Pediatrics, 108(1),44-53.

Albritton, R. (2009). Let Them Eat Junk. New York: Pluto Press.

Alexandratos, N. (1999). World food and agriculture: Outlook for the medium and long term. PNAS - Proceedings of the National Academy of Sciences of the United States of America, 59085914.

American Community Survey. (2014, September). Poverty: 2012 and 2013. Retrieved 5 30, 2015, from U.S. Census Bureau: American Community Survey Briefs:

http://www.census.gov/content/dam/Census/library/publications/2014/acs/acsbr13-01.pdf

American Community Survey. (2016a). Demographic and Housing Estimates. Retrieved 08 17, 2017, from U.S. Census Bureau:

https:/factfinder.census.gov/faces/tableservices/jsf/pages/productview.xhtml?pid=ACS_16_5YR _DP05\&src $=$ pt

American Community Survey. (2016b). Selected Economic Statistics. Retrieved 08 17, 2017 , from U.S. Census Bureau:

https://factfinder.census.gov/faces/tableservices/jsf/pages/productview.xhtml?pid=ACS_16_5YR _DP03\&src=pt

American Community Survey. (2016c). Selected Housing Characteristics American Community Survey 5-Year Estimates. Retrieved 08/17/2017 from

https:/factfinder.census.gov/faces/tableservices/jsf/pages/productview.xhtml?pid=ACS_16_5YR _DP04\&src=pt.

American Diabetes Association. (2015). Type 2 Diabetes. Retrieved 11 15, 2015, from American Diabetes Association: http://www.diabetes.org/diabetes-basics/type-2/?loc=db-slabnav 
Anderson, M. D., \& Cook, J. T. (1999). Community Food Security: Practice in need of theory? Agriculture and Human Values, 16(2), 141-150.

Atkins, P., \& Bowler. (2001). Food in Society. New York: Oxford University Press.

Baltimore City Food Policy Taskforce. (2009). Final Report and Recommendations. Retrieved 1 27, 2015, from Baltimore City Government:

http://cleanergreenerbaltimore.org/uploads/files/Baltimore\%20City\%20Food\%20Policy\%20Task $\% 20$ Force\%20Report.pdf

Banks, K. (2011, August). Framing the Food Landscape of Travis County. Austin, TX: University of Texas.

Bentley, N. L. (1995). Local Food Security: Foodsheds and The Food Circles. Retrieved 8 13, 2014, from http://archive.sare.org/sanet-mg/archives/html-home/7-html/0307.html

Berg, J. (2008). All You Can Eat: How Hungry is America? New York: Seven Stories Press.

Bhattacharya, J., Currie, J., \& Haider, S. (2004). Poverty, Food Insecurity, and Nutritional Outcomes in Children and Adults. Journal of Health Economics, 839-862.

Bickel, G., Nord, M., Price, C., Hamilton, W., \& Cook, J. (2000, August). Guide to Measuring Household Food Security. Retrieved 10 22, 2015, from Food and Nutrition Service of the USDA: http://www.fns.usda.gov/sites/default/files/FSGuide.pdf

Bloom, J. (2010). American Wasteland. Cambridge, MA: Da Capo Press.

Bitton, S., \& Roth, J. (2010). Addressing Food Insecurity. JAMA - Journal of the American Medical Association, 304(21), 2405-2406.

Bloom, J. (2010). American Wasteland. Cambridge, MA: Da Capo Press.

Bollen, A. \& Curran, P. (2006). Latent Curve Models: A Structural Equation Perspective. Hoboken, NJ: John Wiley \& Sons.

Bronte-Tinkew, J., Zaslow, M., Capps, R., Horowitz, A., \& McNamara, M. (2007). Food insecurity works through depression,parenting and infant feeding to influence overweight and health in toddlers. Journal of Nutrition, 137(9), 2160-2165.

Brownell, K. D., Schwartz, M. B., Puhl, R. M., Henderson, K. E., \& Harris, J. L. (2009). The need for bold action to prevent adolescent obesity. The Journal of adolescent health, 45(3), S817.

Burgan, M., \& Winne, M. (2012, September). Doing Food Policy Councils Right: A Guide to Development and Action. Santa Fe, NM: Mark Winne Associates. Retrieved 7 15, 2015, from http://www.markwinne.com/wp-content/uploads/2012/09/FPC-manual.pdf 
Buschman, J. D. (2016, 9 13). Community Food Assessments. Miami, Florida: Unpublished manuscript submitted as partial fulfillment of the requirements for candidacy for Ph.D. in Social Welfare, School of Social Work, Florida International University.

Casey, P., Goolsby, S., \& Berkowitz, C. e. (2004). Maternal depression, changing public assistance, food security, and child health status. 113(2), Pediatrics, 298-304.

CDC see: Centers for Disease Control and Prevention

Center for a Livable Future (CLF). (2015a). Baltimore Food Policy Advisory Committee. Retrieved 1 27, 2015, from Johns Hopkins Center for a Livable Future: http://www.jhsph.edu/research/centers-and-institutes/johns-hopkins-center-for-a-livablefuture/projects/BFPAC/

Center on Budget and Policy Priorities (CBPP). (2017). Republican Plans to Cut Taxes Now, Cut Programs Later Would Threaten Food Assistance Through SNAP. Retrieved 2-9-2018, from Center on Budget and Policy Priorities: https://www.cbpp.org/research/federalbudget/republican-plans-to-cut-taxes-now-cut-programs-later-would-threaten-food

Centers for Disease Control and Prevention (CDC). (2010). Behavioral Risk Factor Surveillance System - Prevalence and Trends Data: Florida 2010 Overweight and Obesity. Retrieved from Centers for Disease Control and Prevention: http://healthyamericans.org/reports/obesity2006/obesity2006report.pdf

Centers for Disease Control and Prevention (CDC). (2011). Frequently asked questions about calculating obesity-related risk. Atlanta: Centers for Disease Control and Prevention.

Centers for Disease Control and Prevention (CDC). (2014). National Diabetes Statistics Report: Estimates of Diabetes and Its Burden in the United States, 2014. Retrieved 11 20, 2015, from Centers for Disease Control and Prevention:

http://www.cdc.gov/diabetes/pubs/statsreport14/national-diabetes-report-web.pdf

Centers for Disease Control \& Prevention (CDC). (2015). Nutrition \& Health of Young People. Retrieved 11 10, 2015 from CDC Centers for Disease Control and Prevention: http://www.cdc.gov/healthyschools/nutrition/facts.htm

Chilton, M., \& Booth, S. (2007). Hunger of the body and hunger of the mind: African American women's perceptions of food insecurity, health and violence. Journal of Nutrition and Education Behavior, 113(2), 116-125.

CLF see: Center for a Livable Future

Cohen, B. (2002, July). Community Food Security Assessment Toolkit. Retrieved 7 15, 2014, from Efan - Electronic Publications from the Food Assistance \& Nutrition Research Program: http://www.ers.usda.gov/media/327699/efan02013_1_.pdf 
Cohen, J., Cohen, P., West, S. G., \& Aiken, L. S. (2013). Applied multiple regression/correlation analysis for the behavioral sciences. Mahwah, NJ: Routledge.

Coleman-Jensen, A., Gregory, C., \& Rabbitt, M. (2015, 9 08). Community Food Security. Retrieved 9 24, 2015, from USDA / ERS: http://www.ers.usda.gov/topics/food-nutritionassistance/food-security-in-the-us/community-food-security.aspx

Coleman-Jensen, A., M. Rabbitt, C. Gregory, and A. Singh. (2015, 9). Household Food Security in the United States in 2014, Economic Research Report No. 194, USDA, ERS, September 2015.

Coleman-Jensen, A., Rabbitt, M., Gregory, C. \& Singh, A. (2016, 9). Household Food Security in the United States in 2015. U.S. Department of Agriculture, Economic Research Service, September 2016. Retrieved 3 12, 2017 from USDA/ERS:

https://www.ers.usda.gov/webdocs/publications/err215/err-215.pdf?v=42636

Coleman-Jensen, A., Rabbitt, M., Gregory, C. \& Singh, A. (2017, 9). Household Food Security in the United States in 2016. U.S. Department of Agriculture, Economic Research Service, September 2017. Retrieved 1 12, 2018 from USDA/ERS:

https://www.ers.usda.gov/publications/pub-details/?pubid=84972

Congressional Budget Office. (2014, January 28). Letter from Congressional Budget Office to Chairman of House Committee on Agriculture. Retrieved from House Committee on

Agriculture:

agriculture.house.gov/sites/republicans.agricutlure.house.gov/files/documents/CBO_Agriculture alAct2014.pdf

Conner, D., \& Levine, R. (2006). Circles of Association: The Connections of Community-Based Food Systems. Journal of Hunger \& Environmental Nutrition, 1(3), 5-25.

DeMuth, S. (1993). Community Supported Agriculture (CSA): An Annotated Bibliography and Resource Guide. Washington D.C.: Alternative Farming Systems Information Center (AFSIC), National Agricultural Library (NAL), USDA.

Dietz, W. (1995). Does hunger cause obesity? Pediatrics, 95(5), 766-767.

Domestic Fair Trade Working Group. (2006, November-December). Principles of Domestic Fair Trade. Cooperative Grocer Network, 127. Minneapolis, MN. Retrieved 1 15, 2016, from http://www.grocer.coop/articles/principles-domestic-fair-trade

Economic Research Service of the United States Department of Agriculture (ERS/USDA). (2011, 12 31). Food Desert Locator. Retrieved from Economic Reseach Service of the United States Department of Agriculture: http://www.ers.usda.gov/data/fooddesert/about.html

Economic Research Service of the United States Department of Agriculture (ERS/USDA). (2013a, April 20). Food Access Research Atlas. Retrieved from USDA Economic Research Service: http:/http://www.ers.usda.gov/data-products/food-access-researchatlas.aspx\#.UXSr6rVvOik 
Egger, G., \& Dixon, J. (2009). Obesity and chronic disease: always offender or often just accomplice? British Journal of Nutrition, 102(8), 1238-42.

Eisinger, P. K. (1998). Toward an End to Hunger in America. Washington, D.C.: Brookings Institution Press.

Ericksen, P. J. (2008). What Is the Vulnerability of a Food System to Global Environmental Change? Ecology \& Society. 13(2), 1-18.

ERS/USDA see: Economic Research Service of th United States Department of Agriculture FAO see: Food and Agriculture Organization of the United Nations

Farm Journal Foundation. (2017, March 16). Farmers Feed the World. Retrieved from http://www.farmersfeedingtheworld.org/agricultures-development-journey/

Feeding America. (2014, 5 1). Hunger \& Poverty Statistics. Retrieved from Feeding America: http://feedingamerica.org/hunger-in-america/hunger-facts/hunger-and-poverty-statistics.aspx

Finn, J. \& Jacobson, Maxine (2003). Just Practice; Steps Toward a New Social Work Program. Journal of Social Work Education, 39(1), 57-78.

Fitzgerald, N., Hromi-Fiedler, A., Segura-Pérez, S., \& Pérez-Escamilla, R. (2011). Food insecurity is related to increased risk of type 2 diabetes among Latinas. Ethnicity and Disease, 21(3), 328-334.

Food and Agriculture Organization of the United Nations (FAO). (2002). Food insecurity: When people must live with hunger and fear starvation. Retrieved from Food and Agriculture Organization of the United Nations (FAO):

ftp://ftp.fao.org/docrep/fao/005/y7352e/y7352e00.pdf

Food and Agriculture Organization of the United Nations (FAO). (2009). The state of food insecurity in the world 2009. Retrieved from Food and Agriculture Organization of the United Nations (FAO): http://www.fao.org/docrep/012/i0876e/i0876e00.htm

Food and Agriculture Organization, International Fund for Agricultural Development and World Food Programme [FAO, IFAD \& WFP]. (2015). The State of Food Insecurity in the World 2015: The multiple dimensions of food security. Retrieved from Food and Agriculture Organization of the United Nations (FAO): http://www.fao.org/docrep/018/i3458e/i3458e.pdf

Food and Nutrition Service (FNS). (2015, 11 6). Supplemental Nutrition Assistance Program National Level Annual Summary. Retrieved 11 12, 2015, from Food and Nutrition Service of the U.S. Department of Agriculture: http://www.fns.usda.gov/pd/supplemental-nutrition-assistanceprogram-snap

Friedman, R. (2008, Fall). Access to Healthy Foods in Low-Income Neighborhoods: Opportunities for Policy. Retrieved 12 15, 2014, from Yale University Rudd Center: 
http://www.ct.gov/dph/lib/dph/hems/nutrition/pdf/yale_rudd_center_access_to_healthy_foods_re port_2008.pdf

Getz, A. (1991). Urban Foodsheds . The Permaculture Activist, 24(October), 26-27.

Gimenez, E.H. (2014, 12 18). We Already Grow Enough Food For 10 Billion People - and Still Can't End Hunger. Retrieved 3 16, 2017 from Huffington Post: http://www.huffingtonpost.com/eric-holt-gimenez/world-hunger_b_1463429.html

Global Hunger Foundation (GHF). (2011). Our Story. Retrieved 11 23, 2011, from Global Hunger Foundation (GHF): http://www.globalhungerfoundation.org/our-story/

Good Food Council of Lewiston-Auburn (GFLA). (2013). Lewiston Community Food Assessment. Retrieved August 5, 2014, from Good Food Council of Lewiston-Auburn: http://goodfood4la.org/resources/communtity-food-assessment/

Gordon, Robert A. (1968). Issues in Multiple Regression. American Journal of Sociology, 73(5), 592-616.

Gottlieb, R., \& Fisher, A. (1996). Community Food Security and Environmental Justice: Searching for a Common Discourse. Agriculture and Human Values, 13(3), 23-32.

Gucciardi, E., Vogt, J. A., DeMelo, M., \& Stewart, D. E. (2009). Exploration of the relationship between household food insecurity and diabetes in Canada. Diabetes Care, 32(12), 2218-2224.

Gunderson, C., A. Crumbaugh, A. Dewey, M. Kato, \& E. Engelhard (2015). Feeding America, Map the Meal Gap 2014: Food Insecurity and Child Food Insecurity Estimates at the County Level. Retrieved from http://www.feedingamerica.org/hunger-in-america/our-research/map-themeal-gap/2014/map-the-meal-gap-2014-exec-summ.pdf

Gunderson, C., Satoh, A., Dewey, A., Kato, M., \& Engelhard, E. (2015). Food Insecurity and Child Food Insecurity Estimates at the County Level; Map the Meal Gap 2016. Chicago: Feeding America. Retrieved 6 13, 2016, from www.feeingamerica.org/mapthegap

Hahm, M. (2018). Retrieved 2 09, 2018 https://finance.yahoo.com/news/81-companiesannounce-wage-hikes-bonuses-afterglow-trump-tax-reform-171148283.html

Hamm, M. W., \& Bellows, A. C. (2003). Community Food Security and Nutrition Educators. Journal of Nutrition Education \& Behavior, 35(1), 37-42.

Handler, J. F., \& Hasenfeld, Y. (2007). Blame Welfare, Ignore Poverty and Inequality. New York: Cambridge University Press.

Hinds, M. d. (1990, July 26). Leftovers Become Sustenance For Needy. Retrieved 11 24, 2011, from New York Times: http://www.nytimes.com/1990/07/26/us/leftovers-become-sustenancefor-needy.html 
Hinrichs, C. C., \& Allen, P. (2008). Selective Patronage and Social Justice: Local Food Consumer Campaigns in Historical Context. Journal of Agricultural and Environmental Ethics, 21(4), 329-352.

HHS see: U.S. Department of Health and Human Services.

Holben, D. L. (2010). Position of the American Dietetic Association: Food Insecurity in the United States. Journal of the American Dietetic Association, 110(9), 1368-1377.

Homenko, D. R., Morin, P. C., Eimicke, J. P., Teresi, J. A., \& Weinstock, R. S. (2010). Food Insecurity and Food Choices in Rural Older Adults Diabetes Receiving Nutrition Education via Telemedicine. Journal of Nutrition Education and Behavior, 42(6), 404-409.

Hope Collaborative. (2009, April 17). A Place with No Sidewalks. Retrieved from Hope Collaborative: http://www.hopecollaborative.net/wp-content/uploads/2015/05/hp_aplacewithnsidewalks.pdf

Howard, L. L. (2010). Does food insecurity at home affect non-cognitive performance at school? A longitudinal analysis of elementary student classroom behavior. Economics of Education Review, 30(1), 157-176.

Huang, J., Kim, Y., \& Birkenmaier, J. (2016). Unemployment and household food hardship in the economic recession. Public Health and Nutrition, 19(3), 511-519.

Jaccard, J. (1998). Interaction effects in factorial analysis of variance. Thousand Oaks, CA: Sage Publications.

Jaccard, J. \& Guilamo-Ramos, V. (2002). Analysis of variance frameworks in clinical child and adolescent psychology: Advanced issues and recommendations. Journal of Clinical Child and Adolescent Psychology, 31(1), 130-146

Jaccard, J., \& Jacoby, J. (2010). Theory construction and model-building skills: A practical guide for social scientists. New York: Guilford Press.

Jacobson, M., \& Hassanein, N. (2004). Food Matters: Farm viability and food consumption in Missoula County. Missoula, MT: The University of Montana School of Social Work and Environmental Studies Program.

Jalonick, M.C. (2016). House Republicans plan to overhaul nation's food stamps program. Retrieved 4 02, 2017 from PBS: http://www.pbs.org/newshour/rundown/house-republicans-planoverhaul-nations-food-stamps-program/

Jones, J. (2017). Retrieved 1 15, 2017. 18 states will increase their minimum wages on January 1, benefiting 4.5 million workers. http://www.epi.org/publication/18-states-will-increase-theirminimum-wages-on-january-1-benefitting-4-5-million-workers/

Jones, T. (2004). The Value of Food Loss in the American Household. Tucson: Bureau of Applied Research in Anthropology, University of Arizona. 
Kantor, L. S. (1999). Community Food Security Programs Improve Food Access. Food Review, 24(1), 20-26. Retrieved 8 25, 2014

Kantor, L. S., Lipton, K., Manchester, A., \& Oliveira, V. (1997). Estimating and Addressing America's Food Losses. Washington D.C.: United States Department of Agriculture.

Kollannoor-Samuel, G. G., Wagner, J. J., Damio, G. G., Segura-Pérez, S. S., \& Chhabra, J. J. (2011). Social support modifies the association between household food insecurity and depression among Latinos with uncontrolled type 2 diabetes. Journal of Immigrant and Minority Health, 13(6), 982-989.

Kotz, N. (1971). Let them eat promises. Garden City, NY: Anchor Books, Doubleday \& Co.

Lang, T. (1998). Toward a Food Democracy. In S. Griffths, Consuming Passions: Food in the Age of Anxiety (p. 13-23). Manchester, UK: Mandolin, Manchester University Press.

Larson, N. I., Story, M. T., \& Nelson, M. C. (2009). Neighborhood Environments disparities in access to healthy foods in the U.S. American Journal of Preventive Medicine, 36(1), 74-81.

Lavizzo-Mourey, R. (2009). The Adolescent Obesity Epidemic. Journal of Adolescent Health, 45(3), S6-7.

Lee, B.A., Iceland, J. \& Sharp, G. (2012). Racial and Ethnic Diversity Goes Local: Charting Change in American Communities Over Three Decades. Retrieved 2 01, 2018, from http://www.russellsage.org/research/reports/racial-ethnic-diversity.

Levi, J., Segal, L. M., St. Laurent, R., Lang, A., \& Rayburn, J. (2012). F as in Fat: How Obesity Threatens America's Future 2012. Washington, D.C.: Trust for America's Health.

Lutz, A., Swisher, M., \& Brennan, M. (2007, May). Defining Community Food Security. Gainesville, FL: IFAS Extension University of Florida. Retrieved 8 20, 2014, from University of Florida IFAS Extension.

Mabachi, N. M., \& Kimminau, K. S. (2012). Leveraging Community-Academic Partnerships to Improve Healthy Food Access in an Urban, Kansas City, Kansas, Community. Progress in Community Health Partnerships: Research, Education and Action, 6(3, Fall), 279-288.

Maddigan, S. L., Feeny, D. H., Majumdar, S. R., Farris, K. B., \& Johnson, J. (2006). Understanding the determinants of health for people with type 2 diabetes. American Journal of Public Health, 96(9), 1649-1655.

Marder, W., \& Chang, S. (2006). Childhood Obesity: Costs, Treatment Patterns, Disparities in Care, and Prevalent Medical Conditions. Retrieved from Thomson Medstat Research Brief: http://www.medstat.com/pdfs/childhood_obesity.pdf

Marjerrison, S., Cummings, E. A., Glanville, N. T., Kirk, S. F., \& Ledwell, M. (2011). Prevalance and associations of food insecurity in children with diabetes mellitus. The Journal of Pediatrics, 158(4), 607-611. 
Marsden, T., \& Morley, A. (2014). Current food questions and their scholarly challenges. In T. Marsden, \& A. Morley, Sustainable Food Systems (pp. 1-29). New York, Abingdon: Routledge.

Martin, K. S., \& Ferris, A. M. (2007). Food Insecurity and Gender are Risk Factors for Obesity. Journal of Nutrition Education and Behavior, 39(1), 31-36.

Martinez, M.J., \& Kawam, E. (2014). A Call to Action for Social Workers: Food Insecurity and Child Health. Social Work, 59(4), 370-372.

Mauro, R. (1990). Understanding L.O.V.E. (left-out variables error). Psychological Bulletin, 108(2), 314-329.

Maxwell, S. (1996). Food Security: A post-modern perspective. Food Policy, 21(2), 155-170.

McCullum, C., Desjardins, E., Kraak, V., Ladipo, P., \& Costello, H. (2005). Evidence-based Strategies to Build Community Food Security. Journal of the American Dietetic Association, 105(2), 278-283.

McFadden, D. T., Conner, D., Deller, S., Hughes, D., Meter, K., Morales, A., . . Tropp, D. (2016, March). The Economics of Local Food Systems: A Toolkit to Guide Community

Discussions, Assessments, and Choices. Retrieved from USDA Agricultural Marketing Service: https://www.ams.usda.gov/sites/default/files/media/Toolkit\%20Designed\%20FINAL\%203-2216.pdf

Melchior, M., Caspi, A., Howard, L. M., Ambler, A. P., Bolton, H., Mountain, N., \& Moffitt, T. E. (2009). Mental Health Context of Food Insecurity: a Representative Cohort of Families with Young Children. Pediatrics, 124(4), e564-72.

Midgley, G. (2006). Systems Thinking for Evaluation. In B. Williams, \& I. Imam, Systems Concepts in Evaluation: An Expert Anthology (pp. 11-34). Point Reyes, California: Edge Press.

Muldoon, K., Duff, P., Fielden, S., \& Anema, A. (2013). Food insufficiency is associated with psychiatric morbidity in a nationally representative study of mental illness of food-insecure Canadians. Society of Psychiatry and Psychiatric Epidemiology, 48(5), 795-803.

NASW see: National Association of Social Workers

National Association of Social Workers (NASW). (2016). Social Justice. Retrieved 4 15, 2016 from https://www.socialworkers.org/pressroom/features/issue/peace.asp

National Heart, Lung and Blood Institute. (1998, September 1). Clinical Guidelines on the Identification, Evaluation and Treatment of Obesity in Adults. Retrieved December 8, 2011, from National Heart, Lung and Blood Institue of the National Institutes of Health: http://www.nhlbi.nih.gov/guidelines/obesity/ob_gdlns.pdf

Naukkarinen, J., Rissanen, A., Kaprio, J., \& Pietiläinen, K. (2011). Causes and consequences of obesity: the contribution of recent twin studies. International Journal of Obesity, 36, 1017-1024. 
NHLBI see: National Heart, Lung and Blood Institute

Nord, M. \& Coleman-Jensen, A. (2014). Prevalence of US Food Insecurity Is Related to Changes in Unemployment, Inflation and the Price of Food - Economic Research Report ERR 167. Washington D.C.: U.S. Department of Agriculture, Economic Research Service.

Nord, M., Andrews, M., \& Carlson, S. (2008). Food Insecurity in the United States 2007. Washington D.C.: United States Department of Agriculture/ Economic Research Service.

Nord, M., \& Coleman-Jensen, A. (2009, November 16). Food Security in the United States: Measuring Household Food Security. Retrieved from ERS/USDA: http://www.ers.usda.gov/Briefing/FoodSecurity/measurement.htm

Ogden, C. L., Carroll, M. D., Kit, B. K., \& Flegal, K. M. (2013a). Prevalence of Obesity and Trends in Body Mass Index Among US Children and Adolescents, 1999-2010. JAMA - Journal of the American Medical Association, 307(5), 483-490.

Ogden, C. L., Carroll, M. D., Kit, B. K., \& Flegal, K. M. (2013b, October). Prevalence of Obesity Among Adults: United States, 2011-2012. Retrieved 6 15, 2015, from Centers for Disease Control and Prevention: http://www.cdc.gov/nchs/data/databriefs/db131.htm\#table Ogden, C. L., Carroll, M. D., Kit, B. K., \& Flegal, K. M. (2015, November). Prevalence of Obesity Among Adults and Youth: United States, 2011-2014; NCHS data brief, no 215.

Retrieved from Centers for Disease Control: https://www.cdc.gov/nchs/data/databriefs/db219.pdf Office of the Surgeon General of the United States. (2001). The Surgeon General's call to action to prevent and decrease overweight and obesity. Retrieved from U.S. Department of Health and Human Services.: http://www.cdc.gov/nccdphp/dnpa/pdf/CalltoAction.pdf

Olson, C. (1999). Nutrition and health outcomes associated with food insecurity and hunger. Journal of Nutrition, 129(Suppl.), 521-524.

OSG see: Office of the Surgeon General

Palmer, A., Smith, J., Haering, S., \& McKenzie, S. (2009, 1 1). Understanding and Addressing Food Security in Southwest Baltimore. Retrieved from Johns Hopkins Center for a Livable Future: http://www.jhsph.edu/research/centers-and-institutes/johns-hopkins-center-for-a-livablefuture/_pdf/projects/cfa/CFA-Southwest.pdf

Pan, L et al. (2009, 7 17). Differences in Prevalence of Obesity Among Black, White, and Hispanic Adults - United States, 2006-2008. Morbidity and Mortality Weekly Report, 58(27), 740-744

Paxton, A. (1994). The Food Miles Report - the dangers of long-distance food transport. Retrieved 8 18, 2014, from Sustain: http://www.sustainweb.org/publications/?id=191 
Peters, J. (1997). Community Food Systems: Working Toward a Sustainable Future. Journal of the American Dietetic Association, 97(9), 955-956.

Pietrobelli, A. (2005, October). Obesity: Definition, Etiology and Assessment. Retrieved from Encyclopedia of Human Nutrition:

http://www.sciencedirect.com.ezproxy.fiu.edu/science/article/pii/B0122266943002337

Polivy, J. (1996). Psychological Consequences of Food Restriction. Journal of the American Dietetic Association, 96(6), 589-592 .

Pothukuchi, K. (2004). Community Food Assessment: A first step in planning for community food security. Journal of Planning Education and Research, 23(4), 356-377.

Pothukuchi, K., Joseph, H., Burton, H., \& Fisher, A. (2002). What's Cooking in Your Food System: A guide to community food assessment. (K. Siedenburg, \& K. Pothukuchi, Eds.) Retrieved 10 24, 2014, from http://foodsecurity.org/CFAguide-whatscookin.pdf

Rasheed, M. (2013). A Brief Look at Poverty in America. Journal of Housing and Community Development, 70(2), 6-11.

Reisch, M. (2012). Intervention with Communities. In C. A. Glisson, C. N. Dulmus, \& K. M. Sowers, Social work practice with groups, communities, and organizations : evidence-based assessments and interventions (pp. 81-131). Hoboken, NJ: Wiley.

Riches, G. (1997). Hunger, food security and welfare policies: issues and debates in First World. Proceedings of the Nutrition Society, 56(1A), 63-74.

Robbins, K.C. (2006). The Nonprofit Sector in Historical Perspective: Traditions of Philanthropy in the West in Powell, W. W., \& Steinberg, R. (2006). The Nonprofit Sector : A Research Handbook (pp. 13-31). New Haven: Yale University Press.

Rose-Jacobs, R., Black, M., \& Casey, P. e. (2009). Household food insecurity: associations with at-risk infant and toddler development. Pediatrics, 121(1), 65-72.

SAMHSA see: Substance Abuse and Mental Health Services Administration

Seifert, K., Heflin, C., Corcoran, M., \& Williams, D. (2001). Food Insufficiency and the Physical and Mental Health of Low-Income Women. Women \& Health, 32(1-2), 159-177.

Seligman, H. K., Bindman, A. B., Vittinghoff, E. E., Kanaya, A. M., \& Kushel, M. B. (2007). Food insecurity is associated with diabetes mellitus-- results from the National Health Examination and Nutrition Examination Survey (NHANES) 1999-2002. Journal of General Internal Medicine, 22(7), 1018-1023.

Seligman, H. K., Davis, T. C., Schillinger, D., \& Wolf, M. S. (2010). Food Insecurity is Associated with Hypoglycemia and Poor Diabetes Self-Management in a Low-Income Sample with Diabetes. Journal of Health Care for the Poor and Underserved, 21(4), 1227-1233. 
Seligman, H. K., Jacobs, E. A., Lopez, A., Sarkar, U., Tschann, J., \& Fernandez, A. (2011). Food insecurity and hypoglycemia among safety net patients with diabetes. Archives of Internal Medicine, 171(13), 1204-1206.

Sen, A. K. (1981). Poverty and famines: An essay on entitlement and deprivation. Oxford: Clarendon Press.

Strauss, W. A. \& Haasl, T. (2018). Economic Outlook Symposium: Summary of 2017 results and 2018 forecasts. Chicago Fed Letter, (391), 1-5.

Stuff, J. E., Casey, P. H., Szeto, K., Gossett, J., Robbins, J., Simpson, P., . . Bogle, M. (2004). Household food insecurity is associated with adult health status. Journal of Nutrition, 134(9), 2330-2335.

Substance Abuse and Mental Health Services Administration (SAMHSA). (2013, July). Community Conversations about Mental Health. Retrieved 11 20, 2015, from SAMHSA: http://www.mentalhealth.gov/talk/community-conversation/information_brief_english_07-2213.pdf\#page $=3 \&$ zoom $=$ auto, $-99,797$

Sullivan, A. F., Clark, S., Pallin, D. J., \& Camargo Jr., C. A. (2010). Food Security, Health, and Medication Expenditures of Emergency Department Patients . The Journal of Emergency Medicine, 38(4), 524-528.

Tanumihardjo, S., Anderson, C., Kaufer-Horwitz, M., Bode, L., Emenaker, N., Haqq, A., .. . Stadler, D. (2007). Poverty, obesity, and malnutrition: an international perspective recognizing the paradox. Journal of American Dietetics Association , 107(11), 1966-72.

The Obesity Society. (2012, March 15). The Need for Increased Obesity Research Funding. Retrieved from The Obesity Society: www.obesity.org

Townsend, M., Peerson, J., Love, B., Achterberg, C., \& Murphy, S. (2001). Food Insecurity is Positively Related to Overweight in Women. Journal of Nutrition, 131(6), 1738-1745.

Trust for America's Health. (2012, September). Bending the Obesity Cost Curve in Florida. Retrieved 5 31, 2015, from Trust for America's Health:

http://www.healthiestweightflorida.com/_documents/bending-the-cost-curve.pdf

Trust for America's Health. (2013). F as in Fat: How Obesity Policies are Failing in America. Retrieved from Trust for America's Health: http://www.healthyamericans.org

UN see: United Nations

United Farm Workers. (1996, November). White Paper - Five Cents for Fairness: The Case for Change in the Strawberry Fields. Retrieved 1 15, 2016, from United Farm Workers: http://www.ufw.org/_board.php?mode=view\&b_code=res_white\&b_no=80 
United Nations (UN). (2011, June 23). The Secretary General's High Level Task Force on the Global Food Security Crisis. Retrieved July 18, 2011, from UN.org:

http://www.un.org/issues/food/taskforce/

United Nations (UN). (1975). United Nations. 1975. Report of the World Food Conference, Rome 5-16 November 1974. New York.

U.S. Bureau of Labor Statistics. (2017, 08 17). Labor Force Data by County, Annual Averages. Retrieved 08 17, 2017 from U.S. Bureau of Labor Statistics: https://www.bls.gov/lau/\#cntyaa

U.S. Census Bureau. (2018, 02 01). County Rurality Level: 2010. Retrieved 02 01, 2018, from U.S. Census Bureau: https://www.census.gov/geo/reference/urban-rural.html

U.S. Department of Agriculture (USDA). (2015, 11 10). Food Deserts. Retrieved 11 10, 2015 , from USDA Agricultural Marketing Service:

http://apps.ams.usda.gov/fooddeserts/foodDeserts.aspx

U.S. Department of Agriculture (USDA). (2017). USDA FY 2018 Budget Summary. Retrieved 12 01, 2017 from: https://www.usda.gov/sites/default/files/documents/USDA-Budget-Summary2018.pdf

U.S. Department of Agriculture (USDA). (2018, 01 24). Perdue Announces USDA's Farm Bill and Legislative Principles for 2018. Retrieved 2 01, 2018, from USDA Press: Press Release No. 0015.18: https://www.usda.gov/media/press-releases/2018/01/24/perdue-announces-usdas-farmbill-and-legislative-principles-2018

U.S. Department of Health and Human Services (HHS). (2015, 5 30). Definition of a Food Desert. Retrieved from ERS/USDA:

http://www.ers.usda.gov/dataFiles/Food_Access_Research_Atlas/Download_the_Data/Archived _Version/archived_documentation.pdf

Ver Ploeg, M., Breneman, V., Dutko, P., Williams, R., Snyder, S., \& Dicken, C. A. (2012). Access to Affordable and Nutritious Food: Updated Estimates of Distance to Supermarkets Using 2010 Data. Washington D.C.: USDA.

Vijayaraghavan, M., Jacobs, E. A., Seligman, H., \& Fernandez, A. (2011). The association between housing instability, food insecurity, and diabetes self-efficacy in low-income adults. Journal of Health Care for the Poor and Underserved , 22(4), 1279-1290.

Vozoris, N. T., \& Tarasuk, V. S. (2003). Household food insufficiency is associated with poorer health. Journal of Nutrition, 133(1), 120-126.

Webb, P., Coates, J., Frongillo, E. A., Rogers, B. L., Swindale, A., \& Bilinsky, P. (2006). Measuring Household Food Insecurity: Why It's So Important and Yet So Difficult to Do. Journal of Nutrition, 136(5), 1404S-1408S. 
Weinfield, N., Mills, G., Borger, C., Gearing, M., Macaluso, T., Montaquila, J., \& Zedlewski, S. (2014, August). Hunger in America 2014. Retrieved from Feeding America:

http://help.feedingamerica.org/HungerInAmerica/hunger-in-america-2014-full-

report.pdf?s_src=W1690RGSC\&s_referrer=google\&s_subsrc=http\%3A\%2F\%2Fwww.feedinga merica.org\%2Fhunger-in-america\%2F\&_ga=1.71637779.1418072502.1473014956

Welsh, J., \& MacRae, R. (1998). Food Citizenship and Community Food Security: Lessons from Toronto, Canada. Canadian Journal of Development Studies , 19(4), 237-255.

Whitaker, R. C., Phillips, S. M., \& Orzol, S. M. (2006). Food Insecurity and the Risks of Depression and Anxiety in Mothers and Behavior Problems in their Preschool-Aged Children. Pediatrics, 118(3), e859-868.

Winne, M. (2003). Community Food Security: Promoting Food Security and Building Healthy Food Systems. Retrieved 8 1, 2014, from Community Food Security Coalition.

Winne, M. (2007, 7). Food Policy Councils. Retrieved from Nourish:

http://www.nourishlife.org/2011/07/food-policy-councils/

Winne, M., Joseph, H., \& Fisher, A. (1997). Community Food Security - A Guide to Concept, Design and Implementation. Venice, CA: Community Food Security Coalition.

Zaslow M, B.-T. J. (2009). Food Security During Infancy: implications for attachment and mental proficiency in toddlerhood. Maternal and Child Health Journal, 13(1), 66-80. 


\section{VITA \\ JOHN D. BUSCHMAN}

1978

1978-1985

1985-1988

1986

1988-1991

1991-1995

1995-2001

2001-2006

2007-2010

2008

2008-2009

2010-2014

2012-2018

2018
B.A. Travel \& Tourism Management

Michigan State University

East Lansing, MI USA

Sales Manager/Director of Sales

Sheraton Hotels Latin America \& Caribbean Division

Rio de Janeiro, Brazil; Cancun, Mexico; St. Maarten, N.A.

Diretor de Marketing, Veplan Hoteis e Turismo

Rio de Janeiro, Recife and Sao Paulo, Brazil

Certificate in Hotel Marketing

Centre International de Glion, Switzerland

Director, Rentamar Turismo

Rio de Janeiro, Brazil and Buenos Aires, Argentina

Vice President, Sales \& Marketing, Networld, Inc.

Livingston/Parsippany, NJ USA

Director, North America

Creative Destination Partners/TUI Group

Miami, FL USA

Director, Group Sales North America

Grupo Posadas

Mexico, D.F. and Dallas, TX USA

Vice President, Americas, ODS Turkey

Miami, FL USA

M.S. Hospitality \& Tourism Management

Florida International University

Miami, FL USA

Adjunct Instructor

International Culinary School

Ft. Lauderdale, FL USA

Director, Platinum DMC Collection

Minneapolis, MN USA

Adjunct Instructor, Lecturer

Chaplin School of Hospitality \& Tourism Management

Florida International University

Miami, FL USA

Ph.D., Social Welfare

Robert Stempel School of Public Health \& Social Work

Florida International University

Miami, FL USA 


\section{PUBLICATIONS AND PRESENTATIONS}

Buschman, J.D. (2016). Sustainable Development within the Meetings \& Hospitality Industry. Panel Discussion. Global Meetings Industry Day, Hollywood, FL

Buschman, J.D. (2015). Let's Talk About Food. Roundtable Presentation, UAA Urban Affairs Association Annual Conference, Miami, FL.

Buschman, J.D. (2015). Case Study 2: Carnival Corporation. Comunicacion en Mercados Globales. Pearson Educacion, Madrid, Spain. P. 59-61

Buschman, J.D. (2014). Food for Thought: Sustainable Practices in Food \& Beverage. Panel Discussion. MPI SEC Southeast Educational Conference, Weston, FL.

Buschman, J.D. (2012). Effective Management of Catering Overproduction can Help Alleviate Food Insecurity in the Community: A Case Study of the South Beach Food \& Wine Festival. Presentation. Coalition of Urban \& Metropolitan Universities (CUMU) 18th Annual Conference. Chattanooga, TN.

Buschman, J.D. \& Kashar, C. (2013). Feed People, Not Landfills: A Case Study of the South Beach Wine \& Food Festival. Poster presentation at The Association for the Advancement of Sustainability in Higher Education (AASHE). Atlanta, GA.

Buschman, J.D. \& Zhao, J. (2008). How does a destination management company enhance teambuilding activities in off-site venues. Poster presentation at The $13^{\text {th }}$ Annual Graduate Education Conference on Hospitality \& Tourism, Orlando FL.

Dev, C.S.; Bowen, J.; Buschman, J.D. (2010). Hospitality Marketing: A Retrospective Analysis (1960-2010) and Predictions (2010-2020). Cornell Hospitality Quarterly, 51 (4), p.459-469.

Dev, C.S.; Thomas, J.H.; Buschman, J.D. \& Anderson, E. (2010). Brand Rights and Hotel Management Agreements: Lessons from Ritz-Carlton Bali's Lawsuit against the RitzCarlton Hotel Company. Cornell Hospitality Quarterly, 51(2), p.215-230.

Yang, K. \& Buschman, J.D. (2017). A Dyadic Perspective on Determinants of Entry Choices in the Global Hospitality Industry. International Journal of Management and Economics. 53(4).

Yang, K. \& Buschman, J.D. (2010). A trade-off? The effect of informal and formal institutional distance on cross-border M\&A transaction value and volume. Roundtable Presentation and Proceedings. Academy of International Business (AIB) Annual Meeting. Rio de Janeiro, Brazil. 